\title{
EVOLUÇÃO RECENTE DA PRESENÇA E DO PERFIL DE MINORIAS NA UNIVERSIDADE FEDERAL DE MINAS GERAIS
}

(D) André Braz Golgher ${ }^{1}$

I Universidade Federal de Minas Gerais (UFMG), Belo Horizonte (MG), Brasil; agolgher@cedeplar.ufmg.br

\section{Resumo}

Foram implementadas políticas de ação afirmativa, incluindo políticas de bônus e cotas na Universidade Federal de Minas Gerais (UFMG), com o intuito de diminuir desigualdades no acesso ao ensino superior. Além disso, o Programa de Apoio a Planos de Reestruturação e Expansão das Universidades (Reuni) e o uso do Exame Nacional do Ensino Médio/Sistema de Seleção Unificado (Enem/SiSU) no processo seletivo podem ter afetado a proporção de estudantes pertencentes às minorias frequentando instituições públicas de ensino superior no Brasil. O principal objetivo deste trabalho é verificar a evolução da diversidade do corpo discente da UFMG no período de 2006 a 2015, abordando os efeitos dessas mudanças. As políticas do Reuni, bônus e cotas parecem ser eficazes na redução das desigualdades de diferentes tipos na UFMG, enquanto o Enem/SiSU parece ter promovido um aumento na desigualdade. Além disso, foram avaliados os determinantes da propensão de pertencer a domicílios de baixa renda, de ser negro ou de ter frequentado escolas de nível médio particulares ou estaduais.

AÇÃO AFIRMATIVA • REUNI • ENEM • COTAS

\section{RECENT EVOLUTION OF MINORITIES' ATTENDANCE AND PROFILE AT UNIVERSIDADE FEDERAL DE MINAS GERAIS}

\section{Abstract}

In order to decrease attendance inequalities at the tertiary level in Brazil, affirmative action policies were implemented, including the bonus and quotas policies at Universidade Federal de Minas Gerais (UFMG). Besides, the Programa de Apoio a Planos de Reestruturação e Expansão das Universidades (Reuni) and the use of Exame Nacional do Ensino Médio/Sistema de Seleção Unificado (Enem/SiSU) in the selection process may have affected the proportion of minorities in public higher education institutions in Brazil. The paper's main objective is to verify the evolution of the student body diversity at UFMG between 2006 and 2015, addressing the effects of these changes. The Reuni, bonus and quota policies seemed to be effective in decreasing inequalities of different sorts at UFMG, while Enem/ $\mathrm{SiSU}$ promoted an increased in attendance's inequality. Moreover, the determinants of the propensity of belonging to low-income households, being Black/Pardo or from private or state secondary schools were assessed. 


\section{EVOLUCIÓN RECIENTE DE LA PRESENCIA Y PERFIL DE LAS MINORÍAS EN LA UNIVERSIDADE FEDERAL DE MINAS GERAIS}

\section{Resumen}

Se han aplicado políticas de acción afirmativa, incluidas las políticas de bonificaciones y cuotas en la Universidad de Federal de Minas Gerais (UFMG), con el fin de reducir las desigualdades en el acceso a la educación superior. Además de eso, el Programa de Apoio a Planos de Reestruturação e Expansão das Universidades (Reuni) y el uso de Exame Nacional do Ensino Médio/Sistema de Seleção Unificado (Enem/SiSU) en el proceso de selección puede haber afectado la proporción de minorías que asisten a instituciones públicas de educación superior en Brasil. El objetivo principal de este trabajo es verificar la evolución de la diversidad del alumnado en la UFMG entre 2006 y 2015, abordando los efectos de esos cambios. Las políticas de Reuni, las bonificaciones y cuotas parecen ser eficaces para reducir las desigualdades de diferentes tipos en la UFMG, mientras que el Enem/SiSU parece haber promovido un aumento de la desigualdad. Además, se evaluaron los determinantes de la propensión a pertenecer a hogares de bajos ingresos, a ser negros o a haber asistido a escuelas secundarias privadas o estatales.

ACCIÓN AFIRMATIVA • REUNI • ENEM • CUOTAS

\section{ÉVOLUTION RÉCENTE DE LA PRÉSENCE DES MINORITÉS ET DE LEUR PROFIL À L'UNIVERSIDADE FEDERAL MINAS GERAIS}

\section{Résumé}

Des politiques de discrimination positive ont été mises en œuvre à l'Universidade Federal du Minas Gerais (UFMG), notamments les bonus et les quotas, afin de réduire les inégalités d'accès à l'enseignement supérieur. En outre, le Programa de Apoio a Planos de Reestruturação e Expansão das Universidades (Reuni) et l'utilisation de l'Exame Nacional do Ensino Médio/Sistema de Seleção Unificado (Enem/SiSU) dans le processus de sélection peuvent avoir contribué à augmenter la proportion de minorités dans les établissements publics d'enseignement supérieur au Brésil. L'objectif principal de ce travail est de vérifier l'évolution de la diversité du corps étudiant à l'UFMG entre 2006 et 2015, en abordant les effets de ces changements. Les politiques du Reuni, des bonus et des quotas semblent être efficaces pour réduire les inégalités de différents ordres à l'UFMG, alors que l'Enem/SiSU semble avoir favorisé une augmentation des inégalités. Par ailleurs ont été évalués les déterminants liés à l'appartenance à des ménages à faible revenu, au fait d'être noir ou d'avoir fréquenté des écoles secondaires privées ou publiques.

ACTION POSITIVE • REUNI • ENEM • QUOTAS 

superior no Brasil nas últimas décadas (Caseiro, 2016; McCowan \& Bertolin, 2020; Schwartzman, 2014). Entretanto, ainda existem diferenças marcantes entre os diferentes grupos populacionais quanto à frequência em instituições públicas de ensino superior no Brasil (Artes \& Ricoldi, 2015; Pedrosa et al., 2007; McCowan \& Bertolin, 2020).

Com o intuito de diminuir essas desigualdades, foram implementadas políticas de ação afirmativa, tais como políticas de bônus e de cotas. Mais especificamente na Universidade Federal de Minas Gerais (UFMG), foi implementada uma política de bônus no período de 2009 a 2012 (Aranha, 2009). Em 2012, essa política foi substituída pela política de cotas em âmbito nacional (Telles \& Paixão, 2013).

Além disso, outras políticas implementadas recentemente, como o aumento no número de vagas promovido pelo Programa de Apoio a Planos de Reestruturação e Expansão das Universidades Federais (Reuni), e a introdução do Exame Nacional do Ensino Médio (Enem) e do Sistema de Seleção Unificado (SiSU), também podem ter afetado a presença de minorias em instituições públicas de educação superior no Brasil (Francis \& Tannuri-Pianto, 2012a, 2012b; Lima \& Machado, 2016; McCowan \& Bertolin, 2020; Nogueira et al., 2017; Silveira et al., 2015; Telles \& Paixão, 2013).

O objetivo principal deste artigo é analisar a evolução da diversidade dos alunos da UFMG entre 2006 e 2015, abordando os efeitos dessas mudanças no processo seletivo dessa instituição. O estudo utiliza registros oficiais da UFMG, com dados de alunos selecionados e matriculados na instituição nesse período. Procurou-se associar essas políticas com a evolução temporal da frequência de alunos que viviam em domicílios de baixa renda, de estudantes brancos e negros, e de estudantes que haviam frequentado escolas de nível médio públicas ou privadas.

O artigo foi dividido em cinco partes além dessa introdução. A segunda seção descreve a revisão da literatura sobre os efeitos de políticas implementadas em processos seletivos de instituições de ensino superior na diversidade de estudantes. A terceira seção detalha as principais políticas implementadas no processo seletivo da UFMG de 2006 a 2015. A metodologia é apresentada na quarta seção e os resultados empíricos são discutidos na seção seguinte. A última seção conclui o artigo.

\section{Revisão da literatura}

O número de estudantes frequentando instituições de ensino superior no Brasil aumentou nas últimas décadas (Caseiro, 2016; McCowan \& Bertolin, 2020; Schwartzman, 2014). Entretanto, a participação no ensino superior no Brasil continua a ser bastante desigual entre diferentes grupos populacionais (Artes \& Ricoldi, 2015; Pedrosa et al., 2007; McCowan \& Bertolin, 2020). Por exemplo, a porcentagem de brasileiros com idade entre 18 e 24 anos que frequentavam faculdades ou universidades variava de $0,83 \%$ para o primeiro quintil de renda até $43,7 \%$ para o último. Para esse mesmo grupo etário, $20,4 \%$ dos brancos ou amarelos frequentavam instituições de ensino superior, enquanto para negros ou indígenas esse percentual era de apenas 5,3\% (Pedrosa et al., 2007). Apesar dessas desigualdades, McCowan e Bertolin (2020) argumentam que o acesso de minorias à educação superior melhorou, em parte devido às políticas de ação afirmativa implementadas recentemente no Brasil e também em função das políticas com foco em instituições privadas, como o Fundo de Financiamento Estudantil (Fies) e o Programa Universidade para Todos (Prouni) (McCowan \& Bertolin, 2020; Francis \& Tannuri-Pianto, 2012a, 2012b; Pedrosa et al., 2007; Telles \& Paixão, 2013). 
Diferentes autores abordaram esses pontos empiricamente. Artes e Ricoldi (2015) analisaram a recente evolução do perfil de estudantes usando dados do Censo Demográfico de 2000 e 2010. As autoras observaram que a proporção de brancos frequentando o ensino terciário era muito superior à de negros, mas que as diferenças tinham diminuído. Similarmente, Caseiro (2016) analisou a influência da raça na proporção de estudantes que se graduavam no ensino médio e iniciavam o ensino superior entre 2004 e 2014. O autor observou que a propensão de brancos frequentando instituições de nível superior era maior que a de negros, mas que as diferenças diminuíram. Essa mesma tendência foi observada em McCowan e Bertolin (2020).

De forma similar, Ribeiro et al. (2015) analisaram transições no sistema educacional. Eles concluíram que negros tinham probabilidade menor de transitar entre os diferentes níveis de ensino, incluindo entre o ensino médio e o superior, mesmo depois de controlados os níveis socioeconômicos. Além disso, os resultados para pretos eram inferiores aos apresentados para pardos. Entretanto, similarmente ao observado por outros autores, Ribeiro et al. (2015) também verificaram uma diminuição geral dos efeitos de raça nas probabilidades de transição.

Nessa mesma linha de raciocínio, Marteleto (2012) estudou as desigualdades educacionais no Brasil de 1982 até 2007. Ela observou que a dicotomia entre brancos e negros persistia, mas havia diminuído. Além disso, as diferenças entre as raças se tornaram não significativas no fim do período analisado. A autora propôs duas explicações para esses resultados - mudanças estruturais e mudanças na classificação de raça - e encontrou evidências para os dois fatos. Com relação à primeira explicação, hiatos socioeconômicos entre brancos e negros decresceram. No caso da segunda, notou-se que a educação provocou um "escurecimento" populacional, uma vez que indivíduos com níveis educacionais mais elevados passaram a ter maior propensão de se autoconsiderarem negros.

Apesar dessa tendência de homogeneização entre as raças observada por esses autores, a proporção de negros tende a ser menor em cursos mais prestigiados (Artes \& Ricoldi, 2015; Ferreira, 2020). Similarmente, Carvalhaes e Ribeiro (2019) e McCowan e Bertolin (2020) observaram que minorias se direcionavam para cursos de menor prestígio social em instituições consideradas de pior qualidade.

Existem ainda outros fatores que impactam a frequência em instituições de ensino superior no Brasil, tais como renda do domicílio, educação dos pais e tipo de arranjo domiciliar. Entretanto, esses fatores podem ser associados com raça (Caseiro, 2016; Silva \& Hasenbalg, 2002). Silva e Hasenbalg (2002) observaram que indivíduos que viviam em domicílios de renda mais elevada, com pessoas de referência com níveis educacionais mais elevados e em domicílios menores tinham maior propensão de progredir de forma mais efetiva no sistema de ensino. Não obstante, foi também observado que os efeitos da renda domiciliar decresceram na probabilidade de transição entre diferentes níveis de ensino (Caseiro, 2016; Marteleto, 2012; Ribeiro et al., 2015).

Os autores citados descreveram alguns dos fatores gerais associados com as diferenças na frequência em instituições de ensino superior. Entretanto, o foco aqui são as consequências de mudanças no processo seletivo, em particular os efeitos de políticas de ação afirmativa na participação de minorias em instituições de ensino superior. Com relação a esse ponto, Epple et al. (2008) analisaram os efeitos do banimento de uma ação afirmativa baseada em raça nos EUA e concluíram que haveria um impacto substancial na composição racial em instituições de ensino superior, com um decréscimo na proporção de negros e na diversidade racial. Similarmente, Long (2004) estudou mudanças no comportamento referente à inscrição em processos seletivos, as quais seriam causadas pelo banimento de uma política de ação afirmativa no Texas e na Califórnia. Ele observou que minorias e não minorias mudaram significantemente seu comportamento e que o hiato entre os resultados desses grupos seria amplificado possivelmente pela menor expectativa de minorias serem aceitas (Dickson, 2006). Bertrand et al. (2010) examinaram um programa de ação 
afirmativa direcionado para indivíduos de castas baixas na Índia. Eles observaram que os inscritos de casta alta que seriam preteridos em favor de estudantes de castas mais baixas eram mais ricos do que esses últimos. Ainda assim, a ação afirmativa excluía os mais pobres dentre os estudantes de castas baixas.

De forma similar, muitos autores associaram políticas de ação afirmativa com o perfil dos estudantes em instituições de ensino superior públicas no Brasil. Piotto e Nogueira (2016) estudaram a política de bônus criada em 2006 na Universidade de São Paulo (USP). Os resultados mostraram que a proporção de estudantes que haviam estudado em escolas públicas de nível médio ou que viviam em domicílios de baixa renda frequentando a universidade havia aumentado. Entretanto, essa mesma tendência não foi constatada para estudantes cujo pai tinha escolaridade baixa. Isso indicou que essas políticas diminuíam os efeitos das dificuldades impostas por um baixo nível socioeconômico, mas eram ineficazes para um pobre background cultural do pai. Francis e Tannuri-Pianto (2012a, 2012b) examinaram a política de cotas na Universidade de Brasília (UnB), implementada em 2004, e notaram que a proporção de negros havia aumentado e que os estudantes preteridos eram de melhor nível socioeconômico. Nessa mesma linha, Ferreira (2020) observou que políticas de ação afirmativa eram efetivas em aumentar a proporção de negros na maioria das universidades brasileiras.

Em particular para a UFMG, Carnevali e Amaral (2016) analisaram se a política de bônus tinha modificado o perfil dos estudantes entre 2011 e 2014 e constataram resultados relativamente estáveis, uma consequência inicialmente não esperada da política. Similarmente, Aranha et al. (2012) analisaram os efeitos da implementação da política de bônus e do Reuni. Antes de ambas as políticas, a proporção de estudantes originados de escolas públicas de nível médio que se inscreviam no processo seletivo da UFMG estava decrescendo. Depois dessas políticas, ocorreu uma tendência de estabilização, com uma proporção próxima de $45 \%$ do total de estudantes. Assim, como enfatizado por Peixoto e Braga (2012), a implementação da política de bônus não alterou a demanda relativa por educação terciária entre as minorias ao contrário do que era esperado. Com relação aos aprovados no processo seletivo, antes da política de bônus, em torno de $25 \%$ do total de estudantes eram originados de escolas secundárias públicas, um número muito inferior ao dos que se inscreviam no processo seletivo. Depois da implementação da política de bônus, a proporção de aprovados dessas escolas aumentou para 47\%, número similar ao dos inscritos.

Os estudos citados descreveram tendências associadas à raça e aos níveis socioeconômicos que impactam na frequência estudantil a instituições de nível superior. Essas tendências têm como determinantes uma série de fatores diretamente relacionados ao processo seletivo. A próxima seção detalha as principais mudanças que ocorreram no processo seletivo da UFMG.

\section{Principais políticas implementadas no processo seletivo da UFMG no período de 2006 a 2015}

O processo seletivo da UFMG sofreu algumas mudanças importantes no período de 2006 a 2015, como brevemente mencionado na introdução. Elas são detalhadas nesta seção e sumariadas no Quadro 1.

Com o objetivo de diminuir desigualdades entre os grupos populacionais quanto à frequência em universidades públicas e aumentar a proporção de estudantes negros/indígenas e daqueles que viviam em domicílios de baixa renda em universidades públicas, muitas instituições brasileiras implementaram políticas de ação afirmativa nas últimas décadas. A Universidade Estadual do Rio de Janeiro (UERJ) foi a primeira a adotar essa política em 2002 e posteriormente políticas similares foram criadas em diversas instituições de ensino superior no Brasil (Telles \& Paixão, 2013).

Mais especificamente na UFMG, foi implantada a política de bônus de 2009 a 2012 (Aranha, 2009). Essa política aumentava em $10 \%$ as notas obtidas no exame de seleção de estudantes que 
haviam cursado os últimos sete anos de educação básica em escolas públicas. Além disso, mais 5\% eram acrescidos às notas para estudantes que se autodeclaravam negros ou indígenas. Com pequenas modificações, essa política foi utilizada até o exame de seleção de 2012. Neste ano foi aprovada a lei federal de cotas, implementada em todas as instituições federais de ensino superior no Brasil (Telles \& Paixão, 2013). Começando no exame de seleção de 2013, pelo menos 12,5\% dos estudantes em cada um dos cursos tinham que ter feito todo o ensino médio em escolas públicas. Esse número aumentou para 25\%, 37,5\% e 50\% em 2014, 2015 e 2016, respectivamente. Desde 2016 essa é a política de ação afirmativa utilizada nas instituições federais de ensino superior no Brasil.

Além dessas políticas de ação afirmativa, outras políticas também podem ter afetado a proporção de estudantes pertencentes a minorias que frequentam instituições de ensino superior no Brasil. Uma delas é o Reuni, que aumentou de forma marcante a quantidade de vagas em universidade federais brasileiras entre 2008 e 2012. Em particular na UFMG, houve um aumento de 4.600 vagas anuais para 6.600 (Aranha et al., 2012; Lima \& Machado, 2016).

Ocorreu ainda uma terceira grande mudança no processo seletivo de instituições públicas de ensino superior no Brasil, que foi a introdução do Enem e do SiSU como principal procedimento para seleção de alunos. Em particular na UFMG, foram duas as principais mudanças desde 2008. Até 2010, o vestibular da UFMG consistia de duas etapas próprias na dita forma tradicional. De 2011 a 2013, os quatro exames do Enem (matemática, linguagem, ciências e humanidades) foram usados como primeira etapa, enquanto a segunda etapa consistia de um exame próprio da UFMG, acrescido da redação do Enem. Desde 2014, os cinco exames do Enem e o SiSU são usados como principal procedimento de seleção de estudantes (Lima \& Machado, 2016; Nogueira et al., 2017; Silveira et al., 2015).

Este artigo analisa dados de inscritos na UFMG entre 2006 e 2015. Assim, as principais mudanças já haviam ocorrido no fim do período analisado. Note-se, entretanto, que os períodos em que as políticas foram implementadas são bastante curtos e diferentes entre si. Por exemplo, a política de bônus foi implantada durante somente quatro anos, período que difere de outras políticas. Além disso, a política de cotas é a política atual vigente, mas, como os dados utilizados no artigo são de 2006 a 2015, ela ainda estava sendo implementada nesse último ano. O Reuni aumentou o número de vagas entre 2009 e 2010. Antes dessa política, o número de vagas era menor e aproximadamente estável; depois dela, continuou a ser aproximadamente constante, mas com valores superiores. O principal método atual de seleção de estudantes é o Enem/SiSU. Na base de dados utilizada, ele havia sido usado por somente três anos, enquanto o tradicional vestibular da UFMG em duas etapas vigorou por cinco anos no período estudado, e o Enem como primeira etapa e o vestibular próprio da UFMG como segunda etapa, por três anos.

Essas diferenças são parcialmente levadas em consideração na discussão dos resultados empíricos porque os dados analisados são para cada ano em separado e foram agrupados para todo o período. Ainda assim, os efeitos das políticas podem ser diferentes dependendo do tempo desde a implementação, e esse fator não foi incorporado na análise dos resultados, sendo uma possível limitação do artigo. Além disso, as políticas interagem entre si. Por exemplo, o efeito da política de bônus pode variar por causa do Reuni. Apesar de reconhecer esse fato, o artigo não inclui interações desse tipo na análise empírica, em parte devido a problemas de colinearidade. 
QUADRO 1

POLÍTICAS DE SELEÇÃO DE ESTUDANTES NA UFMG, DE 2006 A 2015

\begin{tabular}{|c|c|c|c|}
\hline Ano & Políticas de ação afirmativa & Número de vagas & Exame de seleção \\
\hline 2006 & \multirow{3}{*}{ Inexistência de políticas gerais } & \multirow{3}{*}{$\begin{array}{l}\text { Aproximadamente } \\
\text { constante }\end{array}$} & \multirow{5}{*}{ Vestibular da UFMG em duas etapas } \\
\hline 2007 & & & \\
\hline 2008 & & & \\
\hline 2009 & \multirow{4}{*}{ Política de bônus: 10\%/15\% } & \multirow{2}{*}{$\begin{array}{l}\text { Aumentou de forma } \\
\text { marcante }\end{array}$} & \\
\hline 2010 & & & \\
\hline 2011 & & \multirow{6}{*}{$\begin{array}{l}\text { Aproximadamente } \\
\text { constante }\end{array}$} & \multirow{3}{*}{$\begin{array}{l}\text { Enem como primeira etapa e exame } \\
\text { da UFMG como segunda etapa }\end{array}$} \\
\hline 2012 & & & \\
\hline 2013 & Política de cotas: $12,5 \%$ & & \\
\hline 2014 & Política de cotas: $25 \%$ & & \multirow{3}{*}{$\begin{array}{l}\text { Enem/SiSU como principal método de } \\
\text { seleção }\end{array}$} \\
\hline 2015 & Política de cotas: $37,5 \%$ & & \\
\hline 2016 & Política de cotas: $50 \%$ & & \\
\hline
\end{tabular}

Fonte: Dados da pesquisa.

Pode-se enumerar diferentes possibilidades de análise tendo como base o Quadro 1. O processo seletivo não mudou de forma substancial de 2006 a 2008. Entre 2008 e 2009, ocorreram duas mudanças principais no processo seletivo da UFMG: a implementação da política do bônus e o aumento no número de vagas. Entre 2009 e 2010, o número de vagas aumentou ainda mais. O Enem substituiu o exame da UFMG na primeira etapa do processo seletivo em 2011. Entre 2012 e 2013, a política de ação afirmativa mudou de bônus para cotas. A política de cotas aumentou em cobertura entre 2013 e 2016. A segunda etapa do processo seletivo foi suprimida entre 2013 e 2014.

Todas essas mudanças apresentadas no Quadro 1 permitem fazer diferentes comparações com relação à diversidade dos alunos que frequentam a UFMG: 1) quais são os efeitos da implementação da política do bônus? 2) Quais foram os impactos do uso do Enem como primeira etapa do processo seletivo? 3) Quais foram os efeitos do aumento do número de vagas? 4) Quais foram os efeitos da mudança da política de bônus para a política de cotas? 5) Quais foram os impactos do aumento da cobertura da política de cotas? 6) Quais foram os efeitos da supressão da segunda etapa do processo seletivo? Todos esses pontos são abordados empiricamente nesse artigo.

\section{Metodologia}

\section{Base de dados}

O artigo usa bases de dados oficiais da UFMG, que foram desenvolvidas pela Comissão Permanente do Vestibular (Copeve) e pelo Departamento de Registro Acadêmico (DRCA) e têm objetivos administrativos como principal intuito. As bases de dados foram gentilmente cedidas para objetivos científicos e preservam o anonimato dos estudantes. As referidas bases foram adaptadas para as análises empíricas feitas neste estudo, com a criação de novas variáveis e a modificação de muitas outras. Os dados para cada um dos anos foram agrupados em uma única base de dados para todo o período. A referida base contém dados daqueles que foram selecionados e registrados na UFMG no período de 2006 a 2015, além de variáveis demográficas e geográficas e informações sobre políticas afirmativas.

O número final de observações é de 59.281. Entretanto, essas observações não são distribuídas de forma igualitária entre as categorias das diferentes variáveis. Por exemplo, para as variáveis renda 
e tipo de escola de nível médio frequentada, temos: 42,6\% dos estudantes viviam em domicílios de baixa renda e $57,4 \%$ dos estudantes viviam em domicílios de renda mais elevada; $56,5 \%$ dos estudantes haviam estudado em escolas de ensino médio privadas, $28,1 \%$ dos estudantes haviam estudado em escolas de ensino médio estaduais, $10,9 \%$ em escolas federais e somente 4,5\% em escolas municipais. Categorias com poucas observações podem causar resultados imprecisos. Como forma de abordar esse ponto, a Tabela 1 mostra o número de observações para cada categoria de renda e tipo de escola por sexo e cor da pele. O número de observações é relativamente elevado em todas as classificações. As exceções são os indivíduos que não declararam a cor da pele e estudaram em uma escola de nível médio municipal.

\section{TABELA 1}

NÚMERO DE OBSERVAÇÕES PARA CATEGORIAS ESPECÍFICAS DE RENDA DOMICILIAR E TIPO DE ESCOLA DE NÍVEL MÉDIO POR SEXO E COR DA PELE

\begin{tabular}{|c|c|c|c|c|}
\hline & & \multirow{2}{*}{ Cor da pele } & \multicolumn{2}{|c|}{ Sexo } \\
\hline & & & Feminino & Masculino \\
\hline \multirow{6}{*}{$\begin{array}{l}\text { Renda do } \\
\text { domicílio }\end{array}$} & \multirow{3}{*}{$\begin{array}{c}\text { Baixa } \\
\text { (menor que } 2 \mathrm{SM} \text { ) }\end{array}$} & Branco & 5.234 & 3.838 \\
\hline & & Não branco & 8.106 & 6.109 \\
\hline & & Não declarou & 1.019 & 837 \\
\hline & \multirow{3}{*}{$\begin{array}{c}\text { Mais elevada } \\
\text { (igual ou maior que } \\
2 \mathrm{SM} \text { ) }\end{array}$} & Branco & 9.836 & 10.491 \\
\hline & & Não branco & 4.588 & 5.374 \\
\hline & & Não declarou & 1.707 & 1.917 \\
\hline \multirow{12}{*}{ Tipo de escola } & \multirow{3}{*}{ Privada } & Branco & 10.853 & 10.168 \\
\hline & & Não branco & 4.462 & 4.159 \\
\hline & & Não declarou & 1.850 & 1.807 \\
\hline & \multirow{3}{*}{ Estadual } & Branco & 2.833 & 2.291 \\
\hline & & Não branco & 6.017 & 4.513 \\
\hline & & Não declarou & 485 & 456 \\
\hline & \multirow{3}{*}{ Federal } & Branco & 967 & 1.457 \\
\hline & & Não branco & 1.292 & 2.019 \\
\hline & & Não declarou & 298 & 396 \\
\hline & \multirow{3}{*}{ Municipal } & Branco & 417 & 382 \\
\hline & & Não branco & 907 & 763 \\
\hline & & Não declarou & 87 & 85 \\
\hline
\end{tabular}

Fonte: Dados da pesquisa.

\section{Estratégia empírica e variáveis}

A estratégia empírica é dividida em dois tipos de análise. Primeiramente são mostradas de forma descritiva as principais tendências da proporção de estudantes na UFMG em diferentes grupos; depois, os resultados baseados em modelos logísticos. Além disso, definem-se as variáveis nesta seção.

A discussão se inicia com a tendência para estudantes de baixa renda, que são aqueles que viviam em domicílios com renda total inferior a dois salários mínimos (SM). Uma dummy foi criada com essa informação (1 - Baixa renda, 0 - Outros). Note-se, entretanto, que o valor real do SM aumentou entre 2006 e 2015. Assim, tudo constante, é esperado que a proporção de estudantes de baixa renda aumente 
devido a essa valorização real do SM. Esse fato foi levado em consideração em algumas análises com a inclusão do valor real do SM como uma variável contínua.

Depois disso, o artigo descreve a proporção de brancos e negros. A base de dados utilizada segue o padrão do Instituto Brasileiro de Geografia e Estatística (IBGE) e tem informação sobre cor da pele/grupo étnico em cinco categorias: branco, pardo, preto, amarelo e indígena. Estes dois últimos grupos são muito pouco numerosos na UFMG e não são analisados. Como a variável é preenchida por autodeclaração, existe uma sexta possiblidade que engloba aqueles que não quiseram declarar sua cor de pele, que é uma categoria numerosa. Assim, a partir dessa informação, foi criada uma variável categórica (0 - Branco, 1 - Negro, 2 - Não declarou).

Em seguida, são apresentadas as tendências para tipo de administração escolar. Escolas de nível médio no Brasil são classificadas como públicas ou privadas e existem diferenças marcantes entre elas. Por exemplo, Cavalcanti et al. (2010) mostram que o desempen ho escolar de estudantes de escolas públicas é muito inferior ao observado para os estudantes de escolas privadas, mesmo depois de controlados vários fatores. Entre as escolas públicas de nível médio, são três os tipos de administração: estadual, federal e municipal. O desempenho acadêmico dos estudantes originados de escolas federais tende a ser similar ao observado para os estudantes de escolas privadas e muito superior àquele dos estudantes das demais escolas públicas (Golgher, 2010). Essas diferenças no desempenho acadêmico impactam diretamente a possibilidade de alunos de escolas de nível médio se tornarem um estudante do ensino superior. Foi criada uma variável categórica com essa informação (0 - Municipal, 1 - Privada, 2 - Federal, 3 - Estadual).

O estudo com os modelos logísticos complementa a análise descritiva em dois grupos de estudo. No primeiro, os dados de todos os anos são analisados de maneira conjunta, como forma de se verificarem associações gerais entre as políticas implementadas no processo seletivo da UFMG e a propensão do aluno pertencer a cada um dos grupos apresentados e discutidos na análise descritiva. As variáveis dependentes são dummies se o estudante era: de baixa renda ( 1 - Sim, 0 - Não); negro (1 - Sim, 0 - Não); branco (1 - Sim, 0 - Não); originado de escola de nível médio federal (1 - Sim, 0 - Não); originado de escola de nível médio estadual (1 - Sim, 0 - Não); originado de escola de nível médio municipal ( 1 - Sim, 0 - Não). No caso do segundo grupo de estudo, foram selecionadas algumas dessas variáveis.

As variáveis explicativas no primeiro grupo de modelos são as seguintes: se no ano foi aplicado o tradicional vestibular da UFMG em duas etapas ( 1 - Sim, 0 - Não); se o ano era antes, durante ou depois do Reuni ( 1 - Depois, $1 / 2$ - Durante, 0 - Antes); se existia uma política de bônus ( 1 - Sim, 0 - Não); se existia uma política de cotas (1 - Sim, 0 - Não); se o curso era SiSU (1 - Sim, 0 - Não); se o estudante havia sido selecionado para o segundo semestre (1 - Sim, 0 - Não); e uma variável contínua para o valor real do SM.

O segundo grupo de modelos busca observar mudanças temporais a respeito de fatores específicos do domicílio. Os dados são para anos específicos que foram analisados de forma separada: 2006, 2011 e 2015. As variáveis explicativas incluem dummies para: sexo (1 - Masculino, 0 - Feminino); estado civil ( 1 - Solteiro, 0 - Outro); se o estudante havia frequentado escola de nível médio no noturno (1 - Sim, 0 - Não); se o estudante havia frequentado pré-vestibular $(1-\operatorname{Sim}$, 0 - Não); se o estudante já possuía um diploma de graduação em nível superior ( 1 - Sim, 0 - Não); se o estudante possuía os seguintes bens no domicílio empregada doméstica, televisão, geladeira, computador ou carro (1 - Sim, 0 - Não). Os modelos também incluíram variáveis categóricas: cor da pele (0 - Branco, 1 - Negro, 2 - Não declarada); se o estudante sabia ler em língua estrangeira (0 - Não, 1 - Espanhol, 2 - Outra língua, 3 - Mais de uma língua); se o estudante havia trabalhado durante o ensino médio (0 - Não, 1 - Até 20 horas semanais, 2 - Mais de 20 horas semanais); número de pessoas no domicílio: (0 - Uma, 1 - Duas ou três, 2 - Quatro ou cinco, 3 - Seis ou mais); nível de educação formal 
do pai e da mãe (0 - Menos que ensino fundamental, 1 - Fundamental, 2 - Médio, 3 - Superior, 4 - O estudante não sabia); tipo de escola de ensino médio frequentada (0 - Municipal, 1 - Privada, 2 - Federal, 3 - Estadual).

Todas as análises foram realizadas em Stata 12.

\section{Resultados}

\section{Análise descritiva}

Esta seção apresenta as tendências para a proporção de estudantes de baixa renda, brancos, negros, e originados de escolas de nível médio privadas, estaduais ou federais. O objetivo é fornecer uma visão geral dessas tendências e relacioná-las com as mudanças de políticas descritas no Quadro 1.

O Gráfico 1 mostra a tendência para estudantes de baixa renda, a qual é bastante clara. Até 2008, o valor era próximo de 6\%, aumentou de forma marcante entre 2008 e 2012, e depois permaneceu estável entre 2012 e 2015, com valores próximos de 14\%. Como mostrado no Quadro 1, duas políticas foram implementadas em 2009: o Reuni e a política de bônus. Ambas devem ter tido um efeito para explicar essa tendência. A implementação da política de cotas em 2013 parece não ter alterado essa tendência, uma vez que substitui a política de bônus.

\section{GRÁFICO 1}

PROPORÇÃO DE ESTUDANTES DE BAIXA RENDA POR SEMESTRE NA UFMG

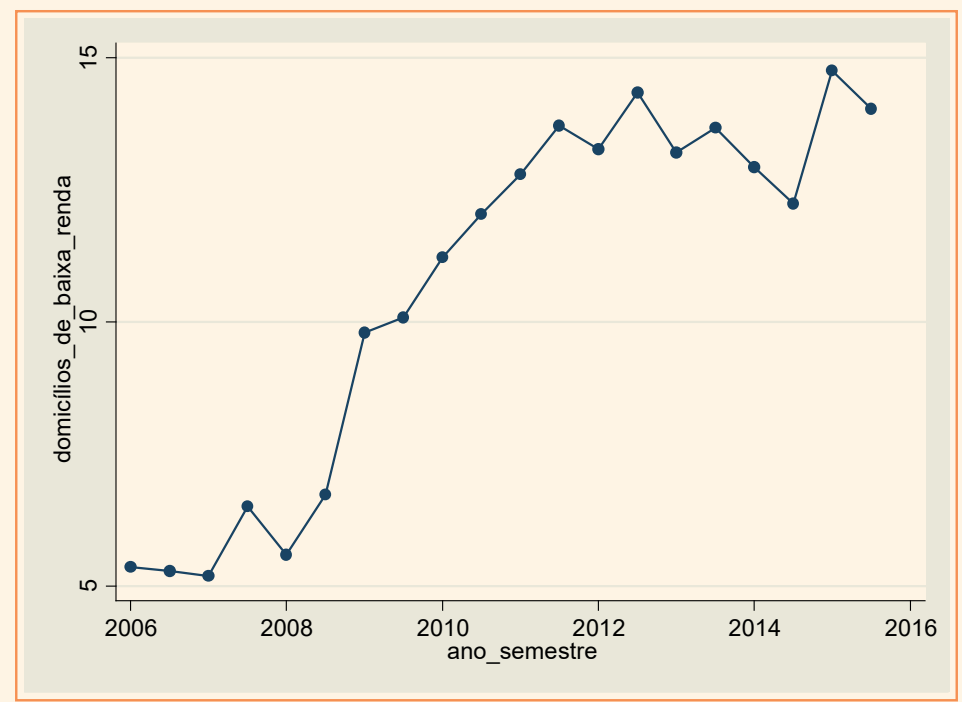

Fonte: Elaboração do autor.

O Gráfico 2 compara a proporção de brancos e de negros. Note-se que ambas as categorias somam $100 \%$. Aqueles que não declararam sua cor foram excluídos aqui. Antes do Reuni e da política de bônus, a proporção de brancos era próxima de 70\%. Depois dessas políticas, até imediatamente antes da implementação do Enem/SiSU, os valores eram de aproximadamente 50\%, e, depois de implantada essa última política, o percentual era próximo de $52 \%$. 


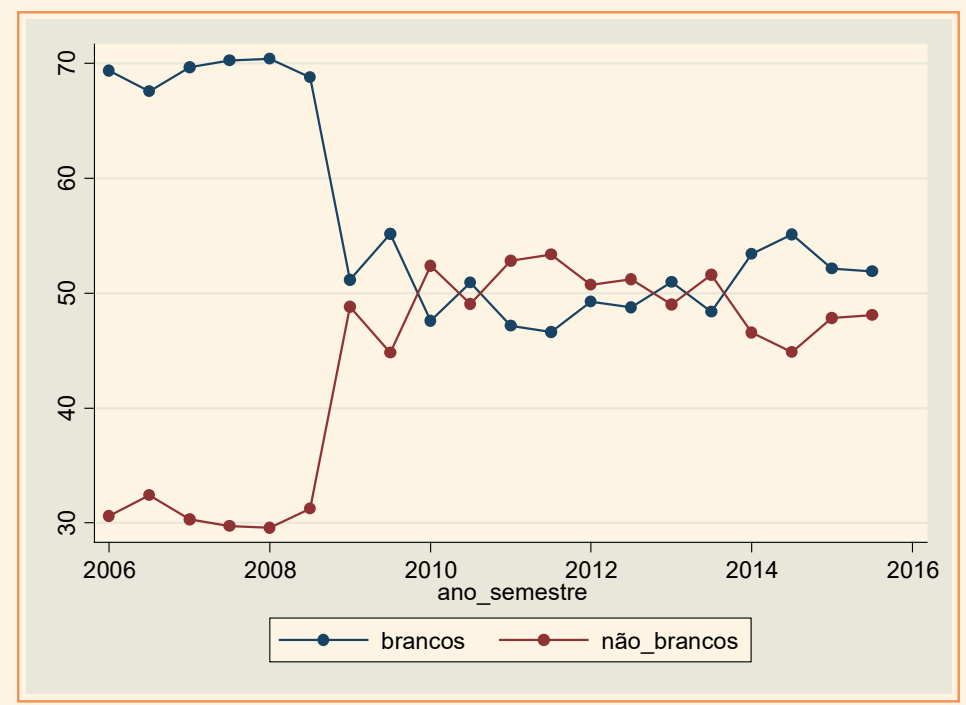

Fonte: Elaboração do autor.

O Gráfico 3 compara as proporções de estudantes originados de escolas de nível médio públicas e privadas. Antes do Reuni e da política de bônus, a proporção de estudantes que haviam estudado em escolas particulares era de aproximadamente $65 \%$, e, depois dessas políticas, os valores oscilavam em torno de 55\%. Essa diminuição foi acompanhada pelo crescimento na proporção de estudantes originados de escolas de nível médio públicas.

\section{GRÁFICO 3}

PROPORÇÃO DE ESTUDANTES ORIGINADOS DE ESCOLAS DE NÍVEL MÉDIO PÚBLICAS E PRIVADAS POR SEMESTRE NA UFMG

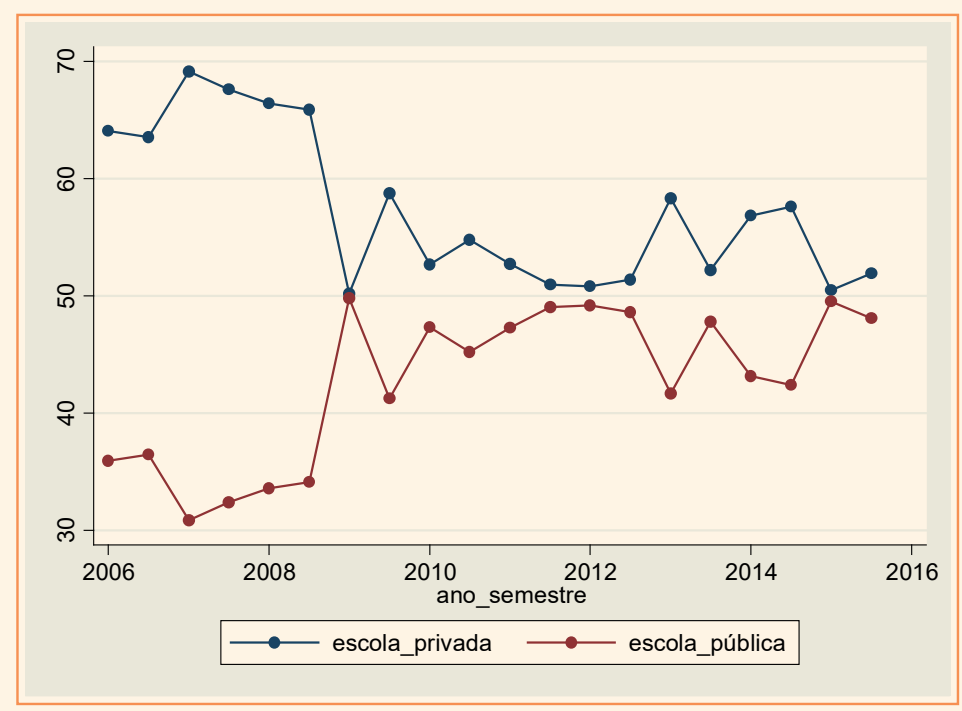

Fonte: Elaboração do autor.

O Gráfico 4 mostra as tendências para brancos e estudantes que haviam estudado o nível médio em escolas privadas. As referidas tendências são muito similares, com uma queda marcante da participação desses estudantes em 2009 e uma razoável estabilidade depois disso. A variação para brancos foi ainda mais acentuada do que para estudantes de escolas privadas, passando de $70 \%$ 
para 50\% nesse ano. Entretanto, note-se que ocorreu um aparente pequeno aumento na proporção de brancos entre 2011 e 2015, possivelmente devido à troca entre as políticas de bônus e de cotas - sendo que esta última ainda estava em processo de implementação - ou à implementação do Enem/SiSU como procedimento principal para seleção de alunos.

\section{GRÁFICO 4}

PROPORÇÃO DE ESTUDANTES BRANCOS E ORIGINADOS DE ESCOLAS DE NÍVEL MÉDIO PRIVADAS POR SEMESTRE NA UFMG

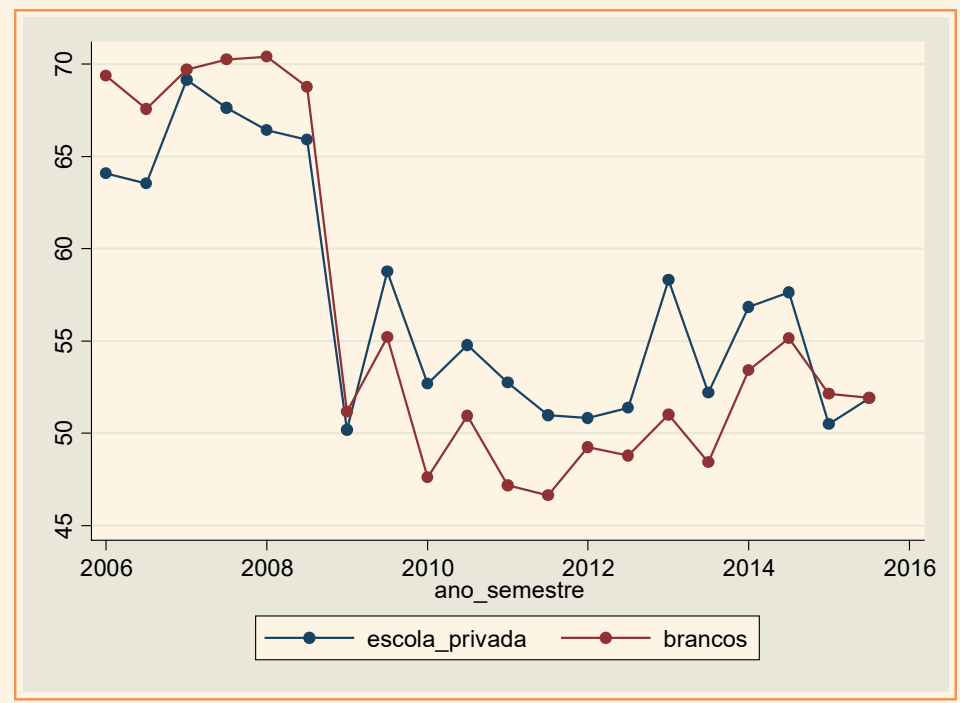

Fonte: Elaboração do autor

O Gráfico 5 mostra a proporção de estudantes de escolas estaduais e federais. Poucos alunos haviam estudado em escolas municipais, e os resultados não são apresentados. Para a proporção de estudantes originados de escolas federais, a tendência difere daquela mostrada no Gráfico 3 para alunos de escolas públicas ou da tendência indicada no Gráfico 5 para estudantes originados de escolas estaduais. As tendências para estudantes de escolas públicas e de escolas estaduais são próximas, em parte porque estes últimos são a grande maioria dos primeiros desde 2009. Para estudantes de escolas federais, observam-se um leve decréscimo entre 2006 e 2013 e um aumento marcante em 2014. Este último ano foi o de implementação do SiSU com a política de cotas. Além disso, pode-se notar que as proporções de estudantes de escolas federais são maiores para os alunos selecionados no primeiro semestre, sugerindo um desempenho acadêmico superior desses quando comparado àquele dos demais estudantes. 


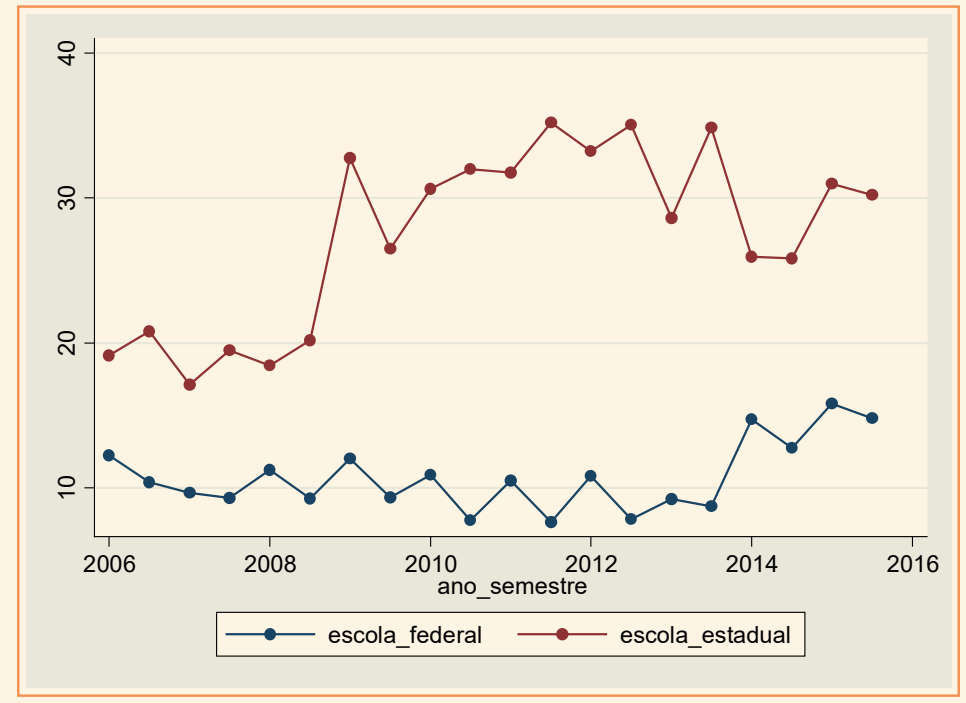

Fonte: Elaboração do autor.

\section{Regressões logísticas}

A Tabela 2 mostra os resultados da aplicação das regressões logísticas para o primeiro grupo de modelos. O objetivo principal é verificar associações entre as diferentes políticas implementadas no processo seletivo da UFMG e a propensão do aluno em pertencer a um grupo particular. Note-se que apenas dois controles foram incorporados aos modelos, que são o valor real do SM no modelo $1 \mathrm{e}$ uma dummy para os estudantes que foram selecionados para o segundo semestre em todos os modelos. Relações entre variáveis sociodemográficas e a propensão em pertencer a grupos distintos são abordadas no segundo grupo de modelos.

Note-se que as variáveis dependentes nos modelos 1 a 6 são respectivamente dummies para: estudantes de baixa renda, negros, brancos, estudantes originados de escolas federais, estudantes originados de escolas estaduais e estudantes originados de escolas municipais. Estudantes que haviam frequentado escolas privadas não podem ser analisados com esses modelos por causa da colinearidade com as políticas de ação afirmativa.

Os coeficientes para o vestibular tradicional da UFMG em duas etapas para estudantes de baixa renda, para negros e para estudantes originados de escolas estaduais ou municipais foram todos negativos; para brancos o coeficiente foi positivo, e para estudantes originados de escolas federais foi não significativo. Ou seja, quando esse tipo de seleção era usado no início do período analisado, ele favorecia brancos e não favorecia os demais grupos populacionais. Estudantes que haviam frequentado escolas de nível médio federais são distintos dos demais estudantes de escola pública, como já mencionado. Esses resultados sugerem pelo menos dois pontos. O primeiro é uma possível tendência temporal em favor dos negros, dos estudantes de baixa renda e dos estudantes originados de escolas estaduais ou municipais (modelos com controles para tendências temporais tiveram problemas de ajuste e os resultados não são mostrados). Ou seja, ocorreu uma homogeneização na competitividade dos diferentes grupos da população, o que é esperado pelo aumento relativo nos níveis educacionais de estudantes com background mais precário. Outro ponto que pode ser levantado é que o vestibular tradicional da UFMG tinha características intrínsecas que favoreciam estudantes brancos e de escolas particulares. 
Inicialmente, esperava-se que o Reuni favorecesse minorias, devido ao aumento no número de vagas, e os resultados mostraram que essa política realmente auxiliou negros e não favoreceu brancos. Entretanto, os demais modelos tiveram coeficientes negativos e significativos. Depois de controlados os efeitos das demais variáveis, o Reuni parece beneficiar não os estudantes de baixa renda ou aqueles que haviam estudado em escolas públicas, mas sim estudantes negros originados de escolas privadas. Uma explicação, ainda que rudimentar, para esse fato é que esses alunos não seriam selecionados pela UFMG quando havia menos vagas e passaram a ser selecionados após o Reuni.

Todos os coeficientes para as políticas de ação afirmativa mostraram o sinal esperado: positivo para estudantes de baixa renda, negros e estudantes de escola pública e negativo para brancos. A magnitude dos coeficientes para a política de cotas, quando comparados com os da política de bônus em cada um dos modelos, sempre foi superior, sugerindo um impacto maior dessa primeira política. Note-se que a política de bônus é efetiva, mas não garante um número mínimo de estudantes de minorias em cada um dos cursos específicos. Como consequência, minorias tendem a ser sub-representadas em cursos mais competitivos na UFMG (Golgher et al., 2015).

A dummy para Enem/SiSU apresentou coeficientes positivos para estudantes originados de escolas federais e negativos para estudantes de baixa renda, negros e aqueles que haviam frequentado escolas estaduais ou municipais. Ou seja, o uso dessa forma de seleção aumentou a proporção de estudantes originados de escolas federais e diminuiu a proporção para os demais tipos de escola pública. O governo federal previu três aspectos positivos da implementação do Enem/SiSU (Nogueira et al., 2017). O primeiro seria que a mobilidade dos estudantes aumentaria, uma vez que, com o mesmo exame, o estudante poderia candidatar-se a qualquer curso em qualquer instituição federal no Brasil. Assim, um estudante de um estado poderia ir estudar em qualquer outro sem fazer exames adicionais. No entanto, Nogueira et al. (2017) e Silveira et al. (2015) concluíram que essas expectativas não foram atendidas. Em particular, o efeito de mobilidade espacial foi observado apenas parcialmente e de forma perversa, uma vez que estudantes que viviam em estados de melhor nível socioeconômico e com melhores escolas de nível médio ocuparam muitas das vagas em instituições de nível superior de regiões com níveis socioeconômicos mais precários.

O controle para estudantes selecionados para o segundo semestre mostrou uma maior propensão de estudantes de baixa renda, negros e originados de escolas estaduais ou municipais e uma menor propensão de estudantes originados de escolas federais para serem selecionados nesse semestre. Esses resultados estão diretamente ligados ao menor desempenho acadêmico de minorias de forma geral e, em particular, no Enem (Golgher, 2010).

Finalmente, o controle para o valor real do SM mostrou um coeficiente positivo, como esperado.

TABELA 2

MODELOS LOGÍSTICOS - PRIMEIRO GRUPO

\begin{tabular}{|c|c|c|c|c|c|c|}
\hline & Modelo 1 & Modelo 2 & Modelo 3 & Modelo 4 & Modelo 5 & Modelo 6 \\
\hline \multirow{2}{*}{ Variáveis explicativas } & \multicolumn{6}{|c|}{ Variável dependente (Dummy) } \\
\hline & Baixa renda & Negros & Brancos & Federal & Estadual & Municipal \\
\hline UFMG 2 etapas & $\begin{array}{c}-0,262 * \star * \\
(0.0326)\end{array}$ & $\begin{array}{c}-0,308 * * * \\
(0,0303)\end{array}$ & $\begin{array}{c}0,223 * \star * \\
(0,0292)\end{array}$ & $\begin{array}{c}-2,43 e-05 \\
(0,0474)\end{array}$ & $\begin{array}{c}-0,591 * \star \star \\
(0,0359)\end{array}$ & $\begin{array}{l}-0,157 * * \\
(0,0626)\end{array}$ \\
\hline Reuni & $\begin{array}{c}-0,186 * \star * \\
(0,0508)\end{array}$ & $\begin{array}{l}0,136 * * * \\
(0,0346)\end{array}$ & $\begin{array}{c}-0,108 * \star \star \\
(0,0326)\end{array}$ & $\begin{array}{c}-0,548 * \star \star \\
(0,055)\end{array}$ & $\begin{array}{c}-0,518 * * * \\
(0,042)\end{array}$ & $\begin{array}{c}-0,536 * * * \\
(0,079)\end{array}$ \\
\hline Bônus & $\begin{array}{l}0,128 * * * \\
(0,00214)\end{array}$ & $\begin{array}{l}0,154^{* * *} \\
(0,00225)\end{array}$ & $\begin{array}{l}-0,138 * * * \\
(0,00235)\end{array}$ & $\begin{array}{c}0,0701 * * * \\
(0,00276)\end{array}$ & $\begin{array}{c}0,191 * * * \\
(0,00225)\end{array}$ & $\begin{array}{c}0,111 * * * \\
(0,00353)\end{array}$ \\
\hline
\end{tabular}


(Continuação)

\begin{tabular}{|c|c|c|c|c|c|c|}
\hline & Modelo 1 & Modelo 2 & Modelo 3 & Modelo 4 & Modelo 5 & Modelo 6 \\
\hline \multirow{2}{*}{ Variáveis explicativas } & \multicolumn{6}{|c|}{ Variável dependente (Dummy) } \\
\hline & Baixa renda & Negros & Brancos & Federal & Estadual & Municipal \\
\hline Cota & $\begin{array}{c}0,300 * * * \\
(0,0128)\end{array}$ & $\begin{array}{c}0,364 * * * \\
(0,0129)\end{array}$ & $\begin{array}{c}-0,324 * * * \\
(0,0134)\end{array}$ & $\begin{array}{c}0,646 * * * \\
(0,0148)\end{array}$ & $\begin{array}{c}0,668 * * * \\
(0,0139)\end{array}$ & $\begin{array}{c}0,337 * * * \\
(0,0275)\end{array}$ \\
\hline SiSU & $\begin{array}{c}-0,183 * \star * \\
(0,0273)\end{array}$ & $\begin{array}{c}-0,0654 * * \\
(0,0258)\end{array}$ & $\begin{array}{l}-0,0389 \\
(0,0250)\end{array}$ & $\begin{array}{c}0,270 * * * \\
(0,0421)\end{array}$ & $\begin{array}{c}-0,190 * * * \\
(0,0312)\end{array}$ & $\begin{array}{c}-0,319 * * * \\
(0,0744)\end{array}$ \\
\hline Segundo semestre & $\begin{array}{l}0,129 * * * \\
(0,0177)\end{array}$ & $\begin{array}{c}0,0754 * * * \\
(0,0182)\end{array}$ & $\begin{array}{c}0,0216 \\
(0,0175)\end{array}$ & $\begin{array}{c}-0,192 * * * \\
(0,0280)\end{array}$ & $\begin{array}{l}0,148 * * * \\
(0,0209)\end{array}$ & $\begin{array}{l}0,167 * * * \\
(0,0405)\end{array}$ \\
\hline Valor real do SM & $\begin{array}{c}0,00203 * * * \\
(0,000241)\end{array}$ & - & - & - & - & - \\
\hline Constante & $\begin{array}{c}-2,260 * * * \\
(0,19)\end{array}$ & $\begin{array}{c}-0,798 * * * \\
(0,0453)\end{array}$ & $\begin{array}{c}0,246 * * * \\
(0,0431)\end{array}$ & $\begin{array}{c}-1,896 * * * \\
(0,0692)\end{array}$ & $\begin{array}{c}-1,115 * * * \\
(0,053)\end{array}$ & $\begin{array}{c}-3,251 * \star * \\
(0,0993)\end{array}$ \\
\hline Observações & \multicolumn{2}{|l|}{59.090} & \multicolumn{4}{|l|}{59.109} \\
\hline
\end{tabular}

Desvios-padrão entre parênteses.

$\star * * p<0,01, * * p<0,05,{ }^{*} p<0,1$

Fonte: Dados da pesquisa.

As tabelas $3 \mathrm{e} 4$ mostram os resultados para as tendências temporais para fatores que determinam a propensão de estudantes de pertencer a grupos específicos. São dois os principais objetivos da análise: verificar esses determinantes; e observar se ocorreram modificações nos determinantes no período de 2006 a 2015.

As primeiras três colunas da Tabela 3 analisam os estudantes de baixa renda em 2006, 2011 e 2015. São observadas algumas tendências gerais para os três anos. Estudantes que não frequentaram pré-vestibular, que não sabiam ler línguas estrangeiras que não fosse o espanhol, com pais e/ou mães com nível educacional baixo, que não tinham empregada doméstica, computador e/ou carro no domicílio, e aqueles que tinham estudado em escolas de ensino médio públicas tinham maior propensão a serem de baixa renda. Sem qualquer surpresa, todos esses fatores são diretamente ligados ao nível socioeconômico dos estudantes.

Outras variáveis também mostraram tendências gerais. Ser do sexo masculino diminuía a propensão de o estudante ser de baixa renda, sugerindo que mulheres de baixa renda são sobrerrepresentadas dentre os estudantes de baixa renda na UFMG. Muitos dos homens de baixa renda podem estar presos a trabalhos de baixa qualificação, impossibilitando investimentos em capital humano. Isso pode indicar que políticas específicas com foco em homens de baixa renda poderiam ser implementadas para facilitar a transição desses indivíduos do nível médio para o superior. Note-se que ter trabalhado mais de 20 horas durante o ensino médio diminui a propensão do estudante a morar em um domicílio de baixa renda, possivelmente porque o estudante contribui de forma significativa com a renda do domicílio. Estudantes que já possuíam um diploma de graduação em ensino superior apresentavam menor propensão de serem de baixa renda. Esses estudantes que buscam um segundo diploma de nível superior tendem a ser mais bem posicionados no mercado de trabalho. Estudantes que viviam em domicílios com mais pessoas tinham menor propensão de serem de baixa renda, muito porque mais indivíduos tendem a somar uma maior renda no domicílio, pois mais pessoas estão no mercado de trabalho. 
O estado civil mostrou resultados significativos para alguns anos. Solteiros mostraram maior propensão de serem de baixa renda em 2011 e em 2015, mas não em 2006, sugerindo que indivíduos jovens em domicílios de baixa renda se tornaram mais propensos a se tornarem estudantes na segunda metade do período analisado. Todas as demais variáveis mostraram resultados não significativos ou não apresentaram tendências claras.

Uma análise similar é feita para negros nas últimas três colunas da Tabela 3. Alguns fatores aumentavam a propensão de o estudante ser negro e mostraram tendências gerais: aqueles que não sabiam ler línguas estrangeiras além do espanhol, aqueles que viviam em domicílios mais numerosos, aqueles que viviam com pai e/ou mãe com baixa escolaridade, aqueles que não tinham empregada doméstica no domicílio e aqueles originados de escolas públicas. Todos esses resultados são esperados, pois estão associados ao nível socioeconômico.

Não foram observadas outras tendências gerais, mas algumas parciais que aumentavam a propensão de o estudante ser negro: ter estudado em escola no período noturno no ensino médio em 2006 e 2011; ter estudado em pré-vestibular em 2011 e 2015; saber ler em espanhol em 2015; não ter carro no domicílio em 2005. Todos esses resultados apontam para a mesma direção: o nível socioeconômico e as oportunidades de negros melhoraram relativamente a brancos.

TABELA 3

MODELOS LOGÍSTICOS - SEGUNDO GRUPO - ESTUDOS TEMPORAIS - PARTE 1

\begin{tabular}{|c|c|c|c|c|c|c|c|}
\hline & & \multicolumn{3}{|c|}{ Modelo 7} & \multicolumn{3}{|c|}{ Modelo 8} \\
\hline \multirow{3}{*}{\multicolumn{2}{|c|}{ Variáveis explicativas }} & \multicolumn{6}{|c|}{ Variável dependente (Dummies) } \\
\hline & & \multicolumn{3}{|c|}{ Baixa renda } & \multicolumn{3}{|c|}{ Negros } \\
\hline & & 2006 & 2011 & 2015 & 2006 & 2011 & 2015 \\
\hline \multicolumn{2}{|c|}{ Masculino } & $\begin{array}{c}-0,311 * * * \\
(0,0886)\end{array}$ & $\begin{array}{c}-0,384 * \star * \\
(0,0668)\end{array}$ & $\begin{array}{c}-0,296 * \star * \\
(0,0672)\end{array}$ & $\begin{array}{c}0,0382 \\
(0,0703)\end{array}$ & $\begin{array}{c}0,0171 \\
(0,0573)\end{array}$ & $\begin{array}{c}0,0652 \\
(0,0562)\end{array}$ \\
\hline \multicolumn{2}{|c|}{ Solteiro } & $\begin{array}{l}0,0895 \\
(0,234)\end{array}$ & $\begin{array}{c}0,516 * * * \\
(0,155)\end{array}$ & $\begin{array}{c}0,461 * * * \\
(0,149)\end{array}$ & $\begin{array}{c}0,270 \\
(0,193)\end{array}$ & $\begin{array}{c}0,443 * * * \\
(0,128)\end{array}$ & $\begin{array}{c}0,179 \\
(0,124)\end{array}$ \\
\hline \multirow{3}{*}{ Cor da pele } & Branco & \multicolumn{6}{|c|}{ Referência } \\
\hline & Negro & $\begin{array}{c}0,0390 \\
(0,0972)\end{array}$ & $\begin{array}{l}0,321 * * * \\
(0,0723)\end{array}$ & $\begin{array}{c}0,108 \\
(0,0732)\end{array}$ & - & - & - \\
\hline & $\begin{array}{c}\text { Não } \\
\text { declarado }\end{array}$ & $\begin{array}{c}0,00105 \\
(0,150)\end{array}$ & $\begin{array}{c}-0,0197 \\
(0,126)\end{array}$ & $\begin{array}{l}0,0341 \\
(0,123)\end{array}$ & - & - & - \\
\hline \multicolumn{2}{|c|}{ Nível médio no noturno } & $\begin{array}{c}0,0632 \\
(0,17)\end{array}$ & $\begin{array}{c}0,345^{* *} \\
(0,137)\end{array}$ & $\begin{array}{c}0,0409 \\
(0,15)\end{array}$ & $\begin{array}{c}0,372 * * * \\
(0,138)\end{array}$ & $\begin{array}{c}0,268 * * \\
(0,111)\end{array}$ & $\begin{array}{c}-0,0595 \\
(0,117)\end{array}$ \\
\hline \multicolumn{2}{|c|}{ Já graduado } & $\begin{array}{c}-0,938 * * * \\
(0,274)\end{array}$ & $\begin{array}{c}-0,715^{\star \star \star} \\
(0,14)\end{array}$ & $\begin{array}{c}-0,687 * \star \star \\
(0,118)\end{array}$ & $\begin{array}{l}-0,134 \\
(0,199)\end{array}$ & $\begin{array}{c}-0,0859 \\
(0,122)\end{array}$ & $\begin{array}{c}-0,213 * * \\
(0,0976)\end{array}$ \\
\hline \multicolumn{2}{|c|}{ Pré-vestibular } & $\begin{array}{c}-0,192 * \\
(0,1)\end{array}$ & $\begin{array}{c}-0,113 * \\
(0,0684)\end{array}$ & $\begin{array}{c}-0,220 * \star \star \\
(0,0673)\end{array}$ & $\begin{array}{c}0,0424 \\
(0,0778)\end{array}$ & $\begin{array}{l}0,132 * * \\
(0,0578)\end{array}$ & $\begin{array}{c}0,112 * * \\
(0,0565)\end{array}$ \\
\hline \multirow{4}{*}{$\begin{array}{c}\text { Leitura } \\
\text { em língua } \\
\text { estrangeira }\end{array}$} & Não & \multicolumn{6}{|c|}{ Referência } \\
\hline & Espanhol & $\begin{array}{c}-0,163 \\
(0,14)\end{array}$ & $\begin{array}{c}-0,389 * \star * \\
(0,113)\end{array}$ & $\begin{array}{c}-0,0687 \\
(0,142)\end{array}$ & $\begin{array}{l}-0,114 \\
(0,118)\end{array}$ & $\begin{array}{c}0,124 \\
(0,0945)\end{array}$ & $\begin{array}{c}0,320 * * * \\
(0,118)\end{array}$ \\
\hline & $\begin{array}{l}\text { Outra } \\
\text { língua }\end{array}$ & $\begin{array}{c}-0,590 * \star * \\
(0,127)\end{array}$ & $\begin{array}{c}-0,701 * * * \\
(0,0994)\end{array}$ & $\begin{array}{c}-0,346 * * * \\
(0,1)\end{array}$ & $\begin{array}{c}-0,206^{*} \\
(0,107)\end{array}$ & $\begin{array}{c}-0,351 * * * \\
(0,0834)\end{array}$ & $\begin{array}{c}-0,272 * * * \\
(0,0820)\end{array}$ \\
\hline & $\begin{array}{c}\text { Mais de } \\
\text { uma }\end{array}$ & $\begin{array}{c}-0,542 * \star * \\
(0,16)\end{array}$ & $\begin{array}{c}-0,786 * * \star \\
(0,113)\end{array}$ & $\begin{array}{c}-0,602 * \star \star \\
(0,114)\end{array}$ & $\begin{array}{c}-0,146 \\
(0,13)\end{array}$ & $\begin{array}{c}-0,487 * * * \\
(0,0961)\end{array}$ & $\begin{array}{c}-0,352 * * * \\
(0,0947)\end{array}$ \\
\hline \multirow{3}{*}{$\begin{array}{l}\text { Trabalhou } \\
\text { durante } \\
\text { o ensino } \\
\text { médio }\end{array}$} & Não & \multicolumn{6}{|c|}{ Referência } \\
\hline & $\begin{array}{l}\text { Até } 20 \\
\text { horas }\end{array}$ & $\begin{array}{c}-0,0340 \\
(0,253)\end{array}$ & $\begin{array}{l}0,0410 \\
(0,142)\end{array}$ & $\begin{array}{l}0,0848 \\
(0,144)\end{array}$ & $\begin{array}{l}0,357 * \\
(0,193)\end{array}$ & $\begin{array}{c}0,0710 \\
(0,12)\end{array}$ & $\begin{array}{l}0,0801 \\
(0,121)\end{array}$ \\
\hline & $\begin{array}{c}\text { Mais de } 20 \\
\text { horas }\end{array}$ & $\begin{array}{c}-0,294 * \star \\
(0,129)\end{array}$ & $\begin{array}{c}-0,253 * * * \\
(0,0964)\end{array}$ & $\begin{array}{c}-0,448 * \star \star \\
(0,0963)\end{array}$ & $\begin{array}{l}0,0536 \\
(0,107)\end{array}$ & $\begin{array}{c}0,0597 \\
(0,0818)\end{array}$ & $\begin{array}{c}0,0995 \\
(0,0794)\end{array}$ \\
\hline
\end{tabular}




\begin{tabular}{|c|c|c|c|c|c|c|c|}
\hline & & \multicolumn{3}{|c|}{ Modelo 7} & \multicolumn{3}{|c|}{ Modelo 8} \\
\hline \multirow{3}{*}{\multicolumn{2}{|c|}{ Variáveis explicativas }} & \multicolumn{6}{|c|}{ Variável dependente (Dummies) } \\
\hline & & \multicolumn{3}{|c|}{ Baixa renda } & \multicolumn{3}{|c|}{ Negros } \\
\hline & & 2006 & 2011 & 2015 & 2006 & 2011 & 2015 \\
\hline \multirow{4}{*}{$\begin{array}{l}\text { Número de } \\
\text { indivíduos } \\
\text { no domicílio }\end{array}$} & Um & \multicolumn{6}{|c|}{ Referência } \\
\hline & $\begin{array}{l}\text { Dois ou } \\
\text { três }\end{array}$ & $\begin{array}{l}-0,491 \\
(0,299)\end{array}$ & $\begin{array}{l}-0,165 \\
(0,216)\end{array}$ & $\begin{array}{c}-0,533 * \star \star \\
(0,201)\end{array}$ & $\begin{array}{l}-0,331 \\
(0,245)\end{array}$ & $\begin{array}{l}0,286 \\
(0,18)\end{array}$ & $\begin{array}{c}0,323 * * \\
(0,154)\end{array}$ \\
\hline & $\begin{array}{l}\text { Quatro ou } \\
\text { cinco }\end{array}$ & $\begin{array}{c}-0,945^{\star \star *} \\
(0,295)\end{array}$ & $\begin{array}{c}-0,665^{\star * *} \\
(0,214)\end{array}$ & $\begin{array}{c}-1,278 * * * \\
(0,202)\end{array}$ & $\begin{array}{l}-0,129 \\
(0,241)\end{array}$ & $\begin{array}{l}0,341 * \\
(0,178)\end{array}$ & $\begin{array}{c}0,349 * * \\
(0,155)\end{array}$ \\
\hline & Seis ou mais & $\begin{array}{c}-1,431 * \star \star \\
(0,322)\end{array}$ & $\begin{array}{c}-1,162 * * * \\
(0,242)\end{array}$ & $\begin{array}{c}-1,808 * * * \\
(0,249)\end{array}$ & $\begin{array}{l}-0,133 \\
(0,259)\end{array}$ & $\begin{array}{c}0,609 * * * \\
(0,203)\end{array}$ & $\begin{array}{c}0,409 * * \\
(0,197)\end{array}$ \\
\hline \multirow{5}{*}{$\begin{array}{l}\text { Escolaridade } \\
\text { do pai }\end{array}$} & $\begin{array}{l}\text { Menos que o } \\
\text { fundamental }\end{array}$ & \multicolumn{6}{|c|}{ Referência } \\
\hline & Fudamental & $\begin{array}{l}-0,206 \\
(0,152)\end{array}$ & $\begin{array}{c}-0,0580 \\
(0,132)\end{array}$ & $\begin{array}{c}-0,271 * \star \\
(0,135)\end{array}$ & $\begin{array}{c}-0,0864 \\
(0,134)\end{array}$ & $\begin{array}{l}-0,157 \\
(0,111)\end{array}$ & $\begin{array}{c}-0,0226 \\
(0,111)\end{array}$ \\
\hline & Médio & $\begin{array}{c}-0,701 * \star * \\
(0,131)\end{array}$ & $\begin{array}{c}-0,425 * \star \star \\
(0,109)\end{array}$ & $\begin{array}{c}-0,552 * \star \star \\
(0,117)\end{array}$ & $\begin{array}{l}0,0943 \\
(0,115)\end{array}$ & $\begin{array}{l}-0,172 * \\
(0,0941)\end{array}$ & $\begin{array}{c}-0,336 * * * \\
(0,0961)\end{array}$ \\
\hline & Superior & $\begin{array}{c}-1,416 * \star \star \\
(0,149)\end{array}$ & $\begin{array}{c}-1,232 * \star \star \\
(0,119)\end{array}$ & $\begin{array}{c}-1,473 * \star * \\
(0,125)\end{array}$ & $\begin{array}{c}-0,387 * * * \\
(0,126)\end{array}$ & $\begin{array}{c}-0,552 * \star \star \\
(0,103)\end{array}$ & $\begin{array}{c}-0,657 * * * \\
(0,103)\end{array}$ \\
\hline & Desconhecida & $\begin{array}{l}0,429 \\
(0,35)\end{array}$ & $\begin{array}{l}0,155 \\
(0,21)\end{array}$ & $\begin{array}{c}0,125 \\
(0,197)\end{array}$ & $\begin{array}{l}-0,148 \\
(0,285)\end{array}$ & $\begin{array}{c}0,120 \\
(0,162)\end{array}$ & $\begin{array}{l}-0,132 \\
(0,143)\end{array}$ \\
\hline \multirow{5}{*}{$\begin{array}{l}\text { Escolaridade } \\
\text { da mãe }\end{array}$} & $\begin{array}{l}\text { Menos que o } \\
\text { fundamental }\end{array}$ & \multicolumn{6}{|c|}{ Referência } \\
\hline & Fundamental & $\begin{array}{c}0,173 \\
(0,168)\end{array}$ & $\begin{array}{c}-0,315^{\star *} \\
(0,143)\end{array}$ & $\begin{array}{c}0,231 \\
(0,154)\end{array}$ & $\begin{array}{c}-0,261 * \\
(0,143)\end{array}$ & $\begin{array}{c}-0,0668 \\
(0,119)\end{array}$ & $\begin{array}{l}-0,108 \\
(0,124)\end{array}$ \\
\hline & Médio & $\begin{array}{l}0,0438 \\
(0,144)\end{array}$ & $\begin{array}{c}-0,328 * * * \\
(0,122)\end{array}$ & $\begin{array}{l}0,0718 \\
(0,127)\end{array}$ & $\begin{array}{c}-0,309 * * \\
(0,122)\end{array}$ & $\begin{array}{c}-0,257 * * \\
(0,101)\end{array}$ & $\begin{array}{l}-0,103 \\
(0,103)\end{array}$ \\
\hline & Superior & $\begin{array}{c}-0,489 * * * \\
(0,159)\end{array}$ & $\begin{array}{c}-0,658 * \star * \\
(0,129)\end{array}$ & $\begin{array}{c}-0,638 * * * \\
(0,132)\end{array}$ & $\begin{array}{c}-0,436 * \star \star \\
(0,135)\end{array}$ & $\begin{array}{c}-0,371 * * * \\
(0,109)\end{array}$ & $\begin{array}{c}-0,425^{* * *} \\
(0,11)\end{array}$ \\
\hline & Desconhecida & $\begin{array}{c}0,122 \\
(0,693)\end{array}$ & $\begin{array}{l}0,0767 \\
(0,344)\end{array}$ & $\begin{array}{c}-0,367 \\
(0,37)\end{array}$ & $\begin{array}{l}-0,575 \\
(0,675)\end{array}$ & $\begin{array}{c}-0,744 * * * \\
(0,274)\end{array}$ & $\begin{array}{l}-0,269 \\
(0,302)\end{array}$ \\
\hline \multicolumn{2}{|c|}{ Empregada doméstica } & $\begin{array}{c}-0,960 * * * \\
(0,131)\end{array}$ & $\begin{array}{c}-1,267 * \star \star \\
(0,0985)\end{array}$ & $\begin{array}{c}-1,692 * \star * \\
(0,143)\end{array}$ & $\begin{array}{l}-0,182 * \star \\
(0,0894)\end{array}$ & $\begin{array}{c}-0,404 * \star \star \\
(0,0773)\end{array}$ & $\begin{array}{c}-0,427 * * * \\
(0,0912)\end{array}$ \\
\hline \multicolumn{2}{|c|}{ TV } & $\begin{array}{c}0,232 \\
(0,476)\end{array}$ & $\begin{array}{l}0,0895 \\
(0,387)\end{array}$ & $\begin{array}{c}-0,828 * * * \\
(0,295)\end{array}$ & $\begin{array}{c}0,549 \\
(0,407)\end{array}$ & $\begin{array}{l}0,542 * \\
(0,308)\end{array}$ & $\begin{array}{c}0,160 \\
(0,222)\end{array}$ \\
\hline \multicolumn{2}{|c|}{ Geladeira } & $\begin{array}{c}0,508 \\
(0,502)\end{array}$ & $\begin{array}{c}-0,856 * * * \\
(0,302)\end{array}$ & $\begin{array}{l}0,0110 \\
(0,313)\end{array}$ & $\begin{array}{c}-0,319 \\
(0,387)\end{array}$ & $\begin{array}{l}0,0948 \\
(0,234)\end{array}$ & $\begin{array}{c}-0,434^{\star} \\
(0,251)\end{array}$ \\
\hline \multicolumn{2}{|c|}{ Computador } & $\begin{array}{c}-0,925 * * * \\
(0,11)\end{array}$ & $\begin{array}{c}-0,681 * * * \\
(0,13)\end{array}$ & $\begin{array}{c}-0,673 * * * \\
(0,219)\end{array}$ & $\begin{array}{c}0,0520 \\
(0,0981)\end{array}$ & $\begin{array}{c}-0,147 \\
(0,0994)\end{array}$ & $\begin{array}{l}-0,162 \\
(0,154)\end{array}$ \\
\hline \multicolumn{2}{|c|}{ Carro } & $\begin{array}{c}-0,990 * * * \\
(0,0977)\end{array}$ & $\begin{array}{c}-1,207 * * * \\
(0,0831)\end{array}$ & $\begin{array}{c}-1,443 * * * \\
(0,0888)\end{array}$ & $\begin{array}{c}-0,291 * * * \\
(0,0868)\end{array}$ & $\begin{array}{l}-0,0693 \\
(0,0703)\end{array}$ & $\begin{array}{c}-0,110 \\
(0,0709)\end{array}$ \\
\hline \multirow{4}{*}{$\begin{array}{l}\text { Tipo de } \\
\text { escola }\end{array}$} & Municipal & \multicolumn{6}{|c|}{ Referência } \\
\hline & Particular & $\begin{array}{c}-1,002 * * * \\
(0,181)\end{array}$ & $\begin{array}{c}-0,791 * * * \\
(0,157)\end{array}$ & $\begin{array}{c}-0,665 * * * \\
(0,196)\end{array}$ & $\begin{array}{c}-0,446 * * * \\
(0,159)\end{array}$ & $\begin{array}{c}-1,287 * * * \\
(0,137)\end{array}$ & $\begin{array}{c}-1,243 * * * \\
(0,171)\end{array}$ \\
\hline & Federal & $\begin{array}{l}0,0391 \\
(0,199)\end{array}$ & $\begin{array}{c}-0,577 * * * \\
(0,175)\end{array}$ & $\begin{array}{l}-0,304 \\
(0,202)\end{array}$ & $\begin{array}{c}-0,0724 \\
(0,175)\end{array}$ & $\begin{array}{l}-0,126 \\
(0,155)\end{array}$ & $\begin{array}{l}-0,666 \\
(0,177)\end{array}$ \\
\hline & Estadual & $\begin{array}{c}0,117 \\
(0,182)\end{array}$ & $\begin{array}{l}0,0695 \\
(0,154)\end{array}$ & $\begin{array}{c}0,293 \\
(0,193)\end{array}$ & $\begin{array}{c}0,00664 \\
(0,158)\end{array}$ & $\begin{array}{c}-0,222^{*} \\
(0,134)\end{array}$ & $\begin{array}{c}-0,280 * \\
(0,168)\end{array}$ \\
\hline \multicolumn{2}{|c|}{ Constante } & $\begin{array}{c}2,860 * * * \\
(0,743)\end{array}$ & $\begin{array}{c}4,668 * * * \\
(0,544)\end{array}$ & $\begin{array}{c}5,217 * * * \\
(0,542)\end{array}$ & $\begin{array}{c}-0,262 \\
(0,6)\end{array}$ & $\begin{array}{c}0,217 \\
(0,422)\end{array}$ & $\begin{array}{c}1,252^{* * *} \\
(0,403)\end{array}$ \\
\hline \multicolumn{2}{|c|}{ Observações } & 4.511 & 6.555 & 6.539 & 4.543 & 6.555 & 6.539 \\
\hline
\end{tabular}

Desvios-padrão entre parênteses.

$* \star * p<0,01, * * p<0,05, * p<0,1$

Fonte: Dados da pesquisa. 
A Tabela 4 é similar à Tabela 3, mas analisa estudantes que haviam cursado o ensino médio em escolas particulares ou estaduais. As primeiras três colunas mostram os resultados para os estudantes de escolas particulares. Algumas variáveis aumentavam a propensão de o estudante ser originado desse tipo de escola com tendências gerais e são associadas com níveis socioeconômicos mais elevados: não ser negro, conhecimento de língua estrangeira, não ter trabalhado mais de 20 horas durante o ensino médio, ter pai e/ou mãe com nível de escolaridade mais elevado, e a presença de empregada doméstica e carro no domicílio. Note-se que a escolaridade da mãe é aparentemente mais decisiva aqui do que nos modelos para baixa renda, sugerindo a maior importância do pai como responsável pela renda do domicílio e da mãe para alocar recursos para educação. Outras tendências gerais foram observadas. Indivíduos que frequentaram pré-vestibular mostraram menor propensão de terem estudado em escolas particulares, indicando que a escolha de estudar em escolas de nível médio públicas e buscar uma melhor preparação para o processo seletivo com pré-vestibular é uma realidade para muitos estudantes. Note-se que esse caminho educacional permite ao estudante utilizar políticas de ação afirmativa e também obter uma melhor preparação para o processo seletivo. Estudantes que frequentaram escolas de ensino médio noturnas tinham menor propensão de terem estudado em escolas particulares, uma vez que escolas particulares são, em sua grande maioria, diurnas.

Algumas tendências parciais também foram notadas. A existência de computador no domicílio mostrou um coeficiente positivo apenas em 2006, indicando que esse bem se tornou insignificante em variar a propensão de o estudante frequentar escolas de ensino médio particulares depois desse ano, isto é, ocorreu um democratização do bem, que se espalhou para os domicílios de estudantes de ensino médio de escolas públicas nos anos 2010. Por outro lado, foi observado para os domicílios mais pobres, representados pela falta de geladeira, um coeficiente negativo em 2015, indicando que esses domicílios não tinham recursos para investir em uma educação particular, mesmo depois de controlados os demais efeitos do modelo. Os coeficientes para o sexo masculino foram em sua maioria negativos e significativos. $O$ resultado indica que ser mulher aumenta a propensão de ter cursado o ensino médio em escolas particulares, sugerindo um maior investimento do domicílio na educação de meninas.

As três últimas colunas da Tabela 4 apresentam os resultados das escolas de ensino médio estaduais. Estudantes que cursaram o ensino médio em escolas federais e municipais são menos numerosos e não são analisados aqui. De forma contrária ao observado para estudantes originados de escolas particulares, os fatores que aumentavam a propensão de estudantes terem realizado o ensino médio em escolas estaduais, que apresentavam tendências gerais e que são associados ao nível socioeconômico foram: ser negro, não ter conhecimento de língua estrangeira, ter trabalhado mais de 20 horas por semana durante o ensino médio, ter pai e/ou mãe com baixo nível de escolaridade e não ter empregada doméstica e/ou carro no domicílio. Outras tendências gerais são também imagens contrárias ao observado para as escolas particulares e mostram a robustez dos resultados. Indivíduos que frequentaram pré-vestibular ou escolas de ensino médio noturnas mostram maior propensão de terem estudado em escolas de ensino médio estaduais.

Com relação às tendências parciais, foi observado um coeficiente negativo para existência de computadores no domicilio apenas em 2006, o que corrobora resultados já encontrados para os estudantes originados de escolas particulares. Um resultado encontrado aqui, porém, acrescenta uma nova perspectiva. A existência de geladeira mostrou um coeficiente negativo apenas para 2006, sugerindo um trade-off para os domicílios muito pobres em ter esse bem em casa ou ir para a escola. Esse trade-off deixa de ser significativo depois disso. 
TABELA 4

MODELOS LOGÍSTICOS - SEGUNDO GRUPO - ESTUDOS TEMPORAIS - PARTE 2

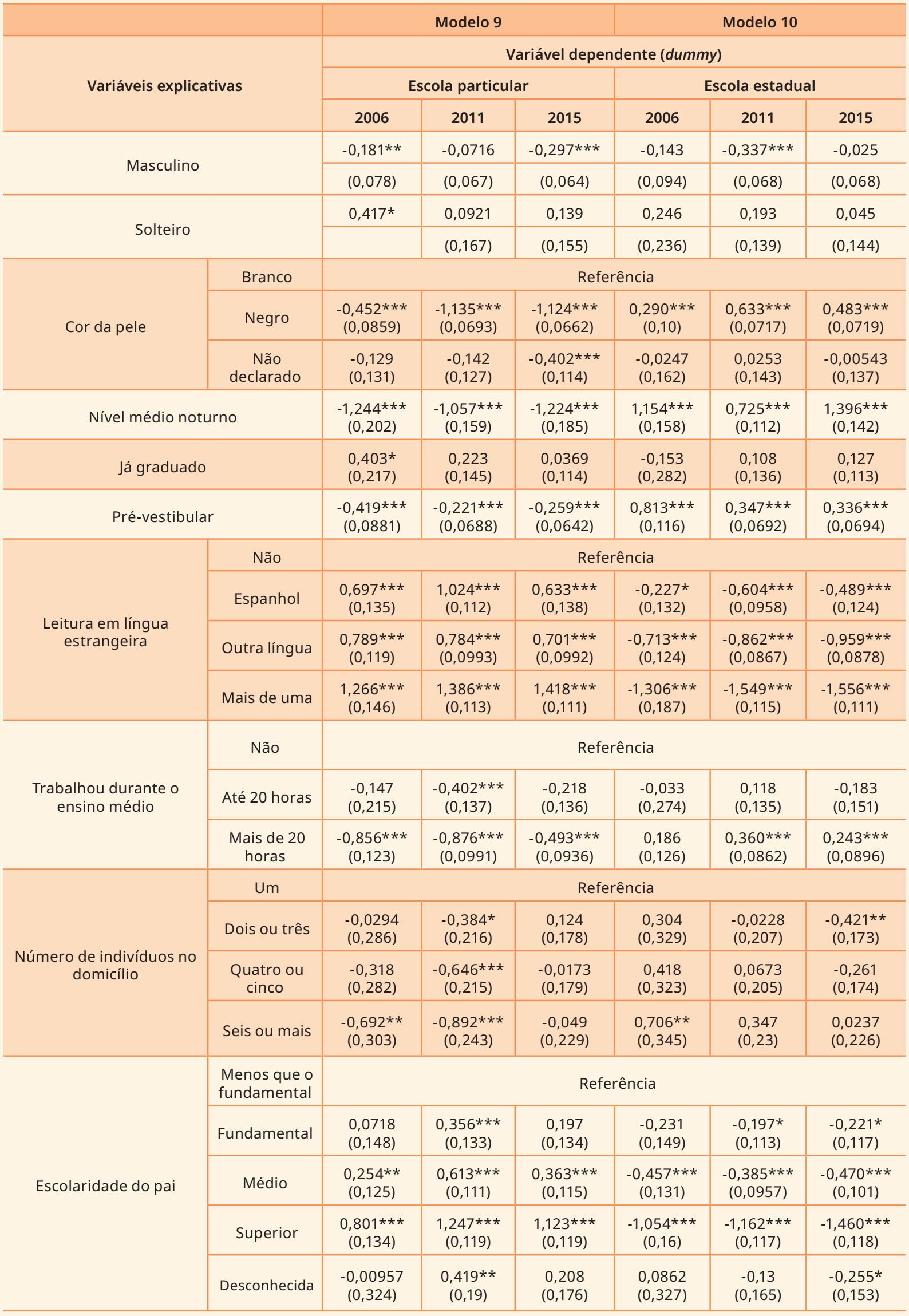




\begin{tabular}{|c|c|c|c|c|c|c|c|}
\hline & & \multicolumn{3}{|c|}{ Modelo 9} & \multicolumn{3}{|c|}{ Modelo 10} \\
\hline & & \multicolumn{6}{|c|}{ Variável dependente (dummy) } \\
\hline \multirow{2}{*}{\multicolumn{2}{|c|}{ Variáveis explicativas }} & \multicolumn{3}{|c|}{ Escola particular } & \multicolumn{3}{|c|}{ Escola estadual } \\
\hline & & 2006 & 2011 & 2015 & 2006 & 2011 & 2015 \\
\hline \multirow{5}{*}{ Escolaridade da mãe } & $\begin{array}{l}\text { Menos que o } \\
\text { fundamental }\end{array}$ & \multicolumn{6}{|c|}{ Referência } \\
\hline & Fundamental & $\begin{array}{c}0,375 * * \\
(0,165)\end{array}$ & $\begin{array}{r}-0,0162 \\
(0,148)\end{array}$ & $\begin{array}{c}0,464 * * * \\
(0,160)\end{array}$ & $\begin{array}{l}-0,123 \\
(0,157)\end{array}$ & $\begin{array}{c}0,186 \\
(0,119)\end{array}$ & $\begin{array}{c}-0,16 \\
(0,132)\end{array}$ \\
\hline & Médio & $\begin{array}{c}0,770 * * * \\
(0,139)\end{array}$ & $\begin{array}{c}0,519 * * * \\
(0,122)\end{array}$ & $\begin{array}{c}0,717 * * * \\
(0,134)\end{array}$ & $\begin{array}{c}-0,671 * * * \\
(0,136)\end{array}$ & $\begin{array}{c}-0,314 * * * \\
(0,101)\end{array}$ & $\begin{array}{c}-0,465 * * * \\
(0,109)\end{array}$ \\
\hline & Superior & $\begin{array}{c}1,130 * * * \\
(0,149)\end{array}$ & $\begin{array}{c}1,004 * * * \\
(0,127)\end{array}$ & $\begin{array}{c}1,060 * * * \\
(0,137)\end{array}$ & $\begin{array}{c}-1,078 * * * \\
(0,162)\end{array}$ & $\begin{array}{c}-0,858 * \star * \\
(0,114)\end{array}$ & $\begin{array}{c}-0,980 * * * \\
(0,119)\end{array}$ \\
\hline & Desconhecida & $\begin{array}{l}1,166^{\star} \\
(0,691)\end{array}$ & $\begin{array}{c}0,301 \\
(0,314)\end{array}$ & $\begin{array}{c}0,311 \\
(0,375)\end{array}$ & $\begin{array}{c}-0,0729 \\
(0,751)\end{array}$ & $\begin{array}{l}-0,185 \\
(0,288)\end{array}$ & $\begin{array}{c}-0,0605 \\
(0,33)\end{array}$ \\
\hline \multicolumn{2}{|c|}{ Empregada doméstica } & $\begin{array}{c}1,041 * * * \\
(0,101)\end{array}$ & $\begin{array}{l}1,057 * \star * \\
(0,0959)\end{array}$ & $\begin{array}{c}1,270 * \star * \\
(0,113)\end{array}$ & $\begin{array}{c}-1,070 * * * \\
(0,159)\end{array}$ & $\begin{array}{c}-1,128 * \star \star \\
(0,127)\end{array}$ & $\begin{array}{c}-1,736 * * * \\
(0,202)\end{array}$ \\
\hline \multicolumn{2}{|l|}{ TV } & $\begin{array}{c}-0,47 \\
(0,455)\end{array}$ & $\begin{array}{c}-0,804^{* *} \\
(0,383)\end{array}$ & $\begin{array}{c}0,316 \\
(0,261)\end{array}$ & $\begin{array}{l}-0,186 \\
(0,459)\end{array}$ & $\begin{array}{l}0,716 * * \\
(0,358)\end{array}$ & $\begin{array}{r}-0,0482 \\
(0,253)\end{array}$ \\
\hline \multicolumn{2}{|c|}{ Geladeira } & $\begin{array}{c}0,539 \\
(0,471)\end{array}$ & $\begin{array}{l}0,0959 \\
(0,273)\end{array}$ & $\begin{array}{c}-0,652 * \star \\
(0,273)\end{array}$ & $\begin{array}{c}-1,371 * * * \\
(0,482)\end{array}$ & $\begin{array}{l}-0,166 \\
(0,257)\end{array}$ & $\begin{array}{c}0,264 \\
(0,289)\end{array}$ \\
\hline \multicolumn{2}{|c|}{ Computador } & $\begin{array}{c}0,513 * * * \\
(0,106)\end{array}$ & $\begin{array}{c}0,052 \\
(0,121)\end{array}$ & $\begin{array}{l}-0,192 \\
(0,182)\end{array}$ & $\begin{array}{c}-0,684^{* * *} \\
(0,109)\end{array}$ & $\begin{array}{c}-0,0213 \\
(0,106)\end{array}$ & $\begin{array}{c}-0,0504 \\
(0,172)\end{array}$ \\
\hline \multicolumn{2}{|l|}{ Carro } & $\begin{array}{l}0,258 * * * \\
(0,0947)\end{array}$ & $\begin{array}{l}0,751 * \star * \\
(0,0808)\end{array}$ & $\begin{array}{l}0,795 * * \star \\
(0,0817)\end{array}$ & $\begin{array}{c}-0,365 * \star * \\
(0,105)\end{array}$ & $\begin{array}{c}-0,633 * * * \\
(0,0734)\end{array}$ & $\begin{array}{c}-0,712 * * * \\
(0,0769)\end{array}$ \\
\hline \multicolumn{2}{|c|}{ Constante } & $\begin{array}{c}-1,641 * \star \\
(0,688)\end{array}$ & $\begin{array}{l}-0,645 \\
(0,482)\end{array}$ & $\begin{array}{c}-1,545 * * * \\
(0,434)\end{array}$ & $\begin{array}{l}1,272 * \\
(0,710)\end{array}$ & $\begin{array}{c}0,104 \\
(0,447)\end{array}$ & $\begin{array}{c}1,382 * \star * \\
(0,429)\end{array}$ \\
\hline \multicolumn{2}{|c|}{ Observações } & 4.543 & 6.555 & 6.539 & 4.543 & 6.555 & 6.539 \\
\hline
\end{tabular}

Desvios-padrão entre parênteses.

$* * * p<0,01, * * p<0,05, * p<0,1$

Fonte: Dados da pesquisa.

Algumas conclusões podem ser tiradas quando todos os quatro grupos de modelos são descritos conjuntamente por variável. Os coeficientes para o sexo masculino foram negativos nos modelos para baixa renda e para escolas privadas; ou seja, ser do sexo feminino aumentou a propensão de o estudante de ser oriundo de uma família de baixa renda e estudar em escolas particulares de ensino médio. Essas características sugerem maiores investimentos em meninas na educação formal e apontam para a confecção de políticas específicas voltadas para jovens do sexo masculino de famílias de baixa renda durante ou após o ensino médio. Os coeficientes para pré-vestibular foram negativos para estudantes de baixa renda e para aqueles oriundos de escolas particulares e positivos para estudantes originados de escolas estaduais. Esses resultados indicam que os alunos que não são de baixa renda mas que estudaram o ensino médio em escola estadual tinham maior propensão a buscar uma melhor preparação para o processo seletivo da UFMG, fazendo o prévestibular, ao mesmo tempo que podiam se beneficiar das políticas de ação afirmativa. Os que estudavam em escolas privadas já tinham uma formação melhor, e os alunos de baixa renda não tinham condições de pagar por esses cursos. Esse fato aponta para políticas específicas de expansão de cursos pré-vestibulares gratuitos ou de baixo custo, embora já existam atualmente alguns desses cursos ministrados por professores voluntários. Os resultados para o conhecimento de línguas estrangeiras mostram uma grande lacuna entre os que frequentavam o ensino médio privado e os alunos de baixa renda, os estudantes negros e aqueles que frequentavam o ensino médio estadual. Essa lacuna pode ser mais bem abordada nas instituições de ensino superior, que em geral dispõem 
de mais recursos para isso, do que nas escolas públicas de ensino médio. Ressalta-se que o Enem tinha, na época em que este trabalho foi redigido, apenas 5 entre 180 questões relacionadas ao idioma estrangeiro, portanto esse conhecimento pode não ser tão decisivo no processo seletivo. Os coeficientes para trabalhar em tempo integral durante a frequência ao ensino médio foram negativos para os estudantes de baixa renda, positivos para os alunos do ensino médio estadual e negativos para os do ensino médio privado. Esses resultados sugerem que os alunos do ensino médio de maior renda não trabalham porque não precisam, como esperado, mas que a falta de emprego para os estudantes de menor renda aumenta sua propensão a pertencer a uma família de baixa renda.

\section{Conclusão}

O Brasil é um país altamente desigual e a frequência em instituições de nível superior varia bastante entre os diferentes grupos populacionais. Muitas instituições no Brasil criaram políticas de ação afirmativa nas últimas décadas com o intuito de minimizar essas desigualdades. Também foi criada a política de cotas em 2012 pelo governo federal com esse mesmo objetivo (Aranha, 2009; Telles \& Paixão, 2013). Além disso, a implementação de outras políticas, como o Reuni e a introdução do Enem/SiSU como principal procedimento para a seleção de estudantes, pode ter afetado a inserção de minorias em instituições de educação superior no Brasil (Lima \& Machado, 2016; Nogueira et al., 2017; Silveira et al., 2015).

Este artigo analisou a evolução da diversidade dos estudantes na UFMG entre 2006 e 2015, abordando os efeitos das mudanças ocorridas no processo seletivo dessa instituição. A proporção de estudantes de baixa renda aumentou de forma marcante entre 2008 e 2013. O Reuni e as políticas de bônus e cotas parecem ter sido efetivas para efetuar essas mudanças, porém a mudança da política de bônus para a política de cotas parece não ter sido decisiva na obtenção desse resultado. As proporções de brancos e de estudantes que frequentaram escolas particulares no ensino médio mostraram tendências similares, com um decréscimo acentuado em 2009. As políticas de bônus e de cotas parecem ter sido efetivas para explicar esses resultados, no entanto o contrário parece ter ocorrido, ainda que de forma mais branda, com a implementação do Enem/SiSU em 2014. A queda na proporção de estudantes originados de escolas particulares de ensino médio foi acompanhada por um aumento na proporção de estudantes que haviam estudado em escolas estaduais. Entretanto, a dinâmica para alunos originados de escolas secundárias federais diferiu, com um crescimento marcante em 2014, ano de implementação do Enem/SiSU, que aparentemente aumentou as desigualdades de frequência à UFMG.

Além disso, foram analisados os determinantes da propensão de ser de baixa renda, negro ou originado de escolas particulares ou estaduais. Como esperado, os níveis socioeconômicos estavam entre esses determinantes. Contudo, os resultados mostraram outros pontos a serem destacados. Ser mulher aumentava a propensão de ser de baixa renda e de estudar em escolas de ensino médio particulares, o que sugere que políticas com foco em jovens do sexo masculino de baixa renda enquanto esses são estudantes de ensino médio ou após a conclusão desse nível podem ser bem-vindas para diminuir desigualdades. Estudantes de renda média e alta que estudavam em escolas de ensino médio estaduais tiveram maior propensão de frequentarem pré-vestibulares, enquanto estudantes de escolas particulares ou de baixa renda mostram uma menor propensão. Esses resultados sugerem que políticas específicas de expansão de pré-vestibulares de baixo custo deveriam ser incentivadas. Os resultados para conhecimento de língua estrangeira mostram grandes diferenças entre estudantes que haviam estudado em escolas particulares de ensino médio e os demais, sugerindo que diminuir essas diferenças deveria ser um dos focos do ensino superior. Concluindo, os resultados empíricos desse artigo apontam para especificidades que podem ser utilizadas para o desenho de políticas públicas com foco na diminuição das desigualdades de frequência no ensino superior no Brasil. 


\section{Referências}

Aranha, A. (2009). Bônus sociorracial na UFMG: Vitória da inclusão e da democracia (Boletim n. 1639). Universidade Federal de Minas Gerais.

Aranha, A., Pena, C., \& Ribeiro, S. (2012). Programas de inclusão na UFMG: O efeito do bônus e do Reuni nos quatro primeiros anos de vigência - Um estudo sobre acesso e permanência. Educação em Revista, 28(4), 317-345. https://doi.org/10.1590/S0102-46982012000400013

Artes, A., \& Ricoldi, A. (2015). Acesso de negros no ensino superior: O que mudou entre 2000 e 2010. Cadernos de Pesquisa, 45(158), 858-881. http://educa.fcc.org.br/pdf/cp/v45n158/1980-5314cp-45-158-00858.pdf

Bertrand, M., Hanna, R., \& Mullainathan, S. (2010). Affirmative action in education: Evidence from engineering college admissions in India. Journal of Public Economics, 94(1-2), 16-29. https://doi.org/10.1016/j.jpubeco.2009.11.003

Carnevali, R., \& Amaral, L. (2016). Políticas de ação afirmativa e as alterações na composição discente: O caso da Universidade Federal de Minas Gerais entre 2011 e 2014. In Anais do 20 Encontro Nacional de Estudos Populacionais (pp. 1-20). Abep.

Carvalhaes, F., \& Ribeiro, C. (2019). Estratificação horizontal da educação superior no Brasil - Desigualdades de classe, gênero e raça em um contexto de expansão educacional. Tempo Social: Revista de Sociologia da USP, 31(1), 195-233. https://doi.org/10.11606/0103-2070.ts.2019.135035

Caseiro, L. (2016). Desigualdade de acesso à educação superior no Brasil e o Plano Nacional de Educação. Instituto Nacional de Estudos e Pesquisas Educacionais Anísio Teixeira.

Cavalcanti, T., Guimaraes, J., \& Sampaio, B. (2010). Barriers to skill acquisition in Brazil: Public and private school students performance in a public university entrance exam. The Quarterly Review of Economics and Finance, 50(4), 395-407. https://doi.org/10.1016/j.qref.2010.08.001

Dickson, L. (2006). Does ending affirmative action in college admissions lower the percent of minority students applying to college? Economics of Education Review, 25(1), 109-119. https://doi.10.1016/j.econedurev.2004.11.005

Epple, D., Romano, R., \& Sieg, H. (2008). Diversity and affirmative action in higher education. Journal of Public Economic Theory 10(4), 475-501. https://doi.org/10.1111/j.1467-9779.2008.00373.x

Ferreira, N. (2020). Desigualdade racial e educação: Uma análise estatística das políticas afirmativas no ensino superior. Educação em Revista, 36, e227734. https://doi.org/10.1590/0102-4698227734

Francis, A., \& Tannuri-Pianto, M. (2012a). The redistributive equity of affirmative action: Exploring the role of race, socioeconomic status, and gender in college admissions. Economics of Education Review, 31, 45-55. https://doi.org/10.1016/j.econedurev.2011.08.005

Francis, A., \& Tannuri-Pianto, M. (2012b). Using Brazil's racial continuum to examine the short-term effects of affirmative action in higher education. Journal of Human Resources, 47(3), 754-784.

Golgher, A. (2010). Diálogos com o ensino médio 6: O estudante de ensino médio no Brasil analisado a partir de dados do Inep (Texto para Discussão, n. 396). Cedeplar/UFMG.

Golgher, A., Amaral, E., \& Neves, A. (2015). Desempenho acadêmico dos estudantes da UFMG: Uma análise da política de bônus sociorracial. Ciências Sociais em Perspectiva, 14(26), 120-145.

https://e-revista.unioeste.br/index.php/ccsaemperspectiva/article/view/9521

Lima, E., \& Machado, L. (2016). Reuni e expansão universitária na UFMG de 2008 a 2012. Educação e Realidade, 41(2), 383-406. https://doi.org/10.1590/2175-623654765

Long, M. (2004). College applications and the effect of affirmative action. Journal of Econometrics, 121(1-2), 319-324. https://doi.org/10.1016/j.jeconom.2003.10.001

Marteleto, L. (2012). Educational inequality by race in Brazil, 1982-2007: Structural changes and shifts in racial classification. Demography, 49(1), 337-358. https://doi.org/10.1007/s13524-011-0084-6 
McCowan, T., \& Bertolin, J. (2020). Inequalities in higher education access and completion in Brazil (Working Paper, n. 2020-3). United Nations Research Institute for Social Development (UNRISD).

Nogueira, C., Nonato, B., Ribeiro, G., \& Flontino, S. (2017). Promessas e limites: O Sisu e sua implementação na Universidade Federal de Minas Gerais. Educação em Revista, 33, Artigo e161036. https://doi.org/10.1590/0102-4698161036

Pedrosa, R., Dachs, J., Maia, R., \& Andrade, C. (2007). Academic performance, students' background and affirmative action at a Brazilian university. Higher Education Management and Policy, 19(3), 1-20. https://doi.org/10.1787/hemp-v19-art18-en

Peixoto, M., \& Braga, M. (2012). Ações afirmativas no ensino superior e o programa de bônus para ingresso nos cursos de graduação da Universidade Federal de Minas Gerais. Revista Brasileira de Estudos Pedagógicos, 93(233), 166-188. https://doi.org/10.24109/2176-6681.rbep.93i233.465

Piotto, D., \& Nogueira, M. (2016). Incluindo quem? Um exame de indicadores socioeconômicos do Programa de Inclusão Social da USP. Educação e Pesquisa, 42(3), 625-649. https://doi.org/10.1590/S15179702201609134896

Ribeiro, C., Ceneviva, R. \& Brito, M. (2015). Estratificação educacional entre jovens no Brasil: 1960 a 2010. In M. Arretche (Ed.), Trajetórias das desigualdades: Como o Brasil mudou nos últimos cinquenta anos (pp. 79-108). Editora Unesp.

Schwartzman, S. (2014). A educação superior e os desafios do século XXI: Uma introdução. In S. Schwartzman (Ed.), A educação superior e os desafios do século XXI (pp. 15-44). Editora da Unicamp.

Silva, N., \& Hasenbalg, C. (2002). Recursos familiares e transições educacionais. Cadernos de Saúde Pública, 18(suppl), 67-76. https://doi.org/10.1590/S0102-311X2002000700008

Silveira, F., Barbosa, M., \& Silva, R. (2015). Exame Nacional do Ensino Médio (Enem): Uma análise crítica. Revista Brasileira de Ensino de Física, 37(1). https://doi.org/10.1590/S1806-11173710001

Telles, E., \& Paixão, M. (2013). Affirmative action in Brazil. LASAFORUM, 14(2), 10-12.

\section{Disponibilidade de dados}

Os dados subjacentes ao texto da pesquisa estão informados no artigo.

\section{Como citar este artigo}

Golgher, A. B. (2021). Evolução recente da presença e perfil de minorias na Universidade Federal de Minas Gerais. Cadernos de Pesquisa, 51, Artigo e07351. https://doi.org/10.1590/198053147531 